Article

\title{
Experimental Study of a Centralized Control Strategy of a DC Microgrid Working in Grid Connected Mode
}

\author{
Robert Salas-Puente *, Silvia Marzal, Raúl González-Medina, Emilio Figueres and \\ Gabriel Garcera \\ Grupo de Sistemas Electrónicos Industriales del Departamento de Ingeniería Electrónica, \\ Universitat Politècnica de València, Camino de Vera s/n, 46022 Valencia, Spain; silmarro@upv.es (S.M.); \\ raugonme@upv.es (R.G.-M.); efiguere@eln.upv.es (E.F.); ggarcera@eln.upv.es (G.G.) \\ * Correspondence: rosapue1@posgrado.upv.es; Tel.: +34-(96)-3877007 (ext. 76021)
}

Received: 18 September 2017; Accepted: 12 October 2017; Published: 17 October 2017

\begin{abstract}
The results concerning the integration of a set of power management strategies and serial communications for the efficient coordination of the power converters composing an experimental DC microgrid is presented. The DC microgrid operates in grid connected mode by means of an interlinking converter. The overall control is carried out by means of a centralized microgrid controller implemented on a Texas Instruments TMS320F28335 DSP. The main objectives of the applied control strategies are to ensure the extract/inject power limits established by the grid operator as well as the renewable generation limits if it is required; to devise a realistic charging procedure of the energy storage batteries as a function of the microgrid status; to manage sudden changes of the available power from the photovoltaic energy sources, of the load power demand and of the power references established by the central controller; and to implement a load shedding functionality. The experimental results demonstrate that the proposed power management methodology allows the control of the power dispatch inside the DC microgrid properly.
\end{abstract}

Keywords: DC microgrid; central controller; power management; power converters

\section{Introduction}

In the context of increasing demand for electric power, local energy production through the integration of microgrids (MGs) in the main grid is becoming an interesting research topic. MGs are formed by various distributed generators (DGs), energy storage systems (ESS) and controllable loads. Distributed Generators can include Renewable Energy Sources (RESs). There are several renewable generation technologies that can provide electricity in a distributed manner, including photovoltaic (PV) systems, micro hydropower, small-scale biomass facilities, small wind turbines, etc. MGs can operate either in grid-connected or in islanded mode, i.e., connected or disconnected from the Point of Common Coupling (PCC). An MG can be disconnected from the main grid in the case of faults [1,2]. Once the fault has disappeared, it can be reconnected to the grid. In addition, a microgrid has its own control system to ensure the correct operation and coordination of the different devices.

Currently, MGs have several configurations: AC, DC or Hybrid AC/DC. However, in some applications DC microgrids have become more attractive than traditional AC microgrids $[3,4]$ because of their higher energy efficiency, their ability to easily connect DC/DC converters to the common DC bus, and their ability to directly couple DC power sources, like batteries and PV sources, with DC loads, which results in a reduction of power conversion losses and costs [4]. Moreover, the control system of DC/DC converters connected to DC microgrid does not have to deal with the problems caused by reactive power flow, synchronization and frequency regulation [5]. A DC microgrid can operate in grid-connected mode by means of an InterLinking Converter (ILC), which connects the DC bus to the PCC of the main grid [6,7]. In this mode, the DC bus voltage is regulated by the ILC, being 
highly stable, even in the case of low quality distribution grids [8]. When the distribution grid fails, the microgrid must regulate the DC bus voltage without the ILC. Some control methods have been developed and proposed in the literature [9-11] for reaching this goal. The typical objectives of the DC microgrid in grid-connected mode are: to minimize the cost of the imported energy from the main grid, to optimize the power dispatch among the converters and the DC bus and to regulate the DC bus voltage [12]. For the optimization of the power dispatch, communications between the devices of the MG and the grid operator are necessary [13,14].

Regarding the control system, one of the main challenges in MGs is how to maintain the generation and consumption energy balance [15]. Power imbalance is a common scenario in MGs, which is caused by the discontinuous power generation availability caused in turn by the intermittent nature of renewables and the variable power demand of the loads connected to the MG, among other factors. These imbalances should be managed fast, safely and effectively by the MG control in order to avoid electrical transients, which can damage or destabilize the system [6-8]. Therefore, proper power management control strategies have been developed. These strategies are aimed mainly at: (i) controlling the connected DGs and energy storage system, (ii) regulating the DC bus voltage, (iii) optimizing the power dispatch between DC/DC converters and the DC bus voltage to minimize the cost of imported energy from the main grid, (iv) managing and optimizing the ESS operation, and (v) managing current sharing between parallel converters $[16,17]$. At present, the major control strategies to maintain power balance in DC microgrids are the well-known droop control methods [14-18], which don't require any communication infrastructure, or other solutions using communications [2]. The power management of MGs can be classified into three categories: centralized, decentralized and distributed control [17-21]. Centralized control systems offer a higher precision of the power sharing among the power converters in MGs [20,21]. In those systems, the energy dispatch can be observed and managed by an intelligent centralized system [22,23]. A microgrid central controller (MGCC) acquires system data and takes decisions about the power to be managed by each of the power converters under operation, forecasting power references to all the power devices of the MG such as DGs, loads, ESS, etc. In the case of communication lost or even the failure of the MGCC, local autonomous controllers are necessary. These controls have been explained in many previous works [24-27], most of them being based on some droop strategies [14]. It is worth pointing out that this paper is focused on a centralized MGCC algorithm. A future work could deal with the coordinated operation of the centralized algorithm with local droop controllers in the case of system failures. However, that study is beyond the scope of this paper. Besides, some previous works $[1,20]$ recommend centralized solutions for small scale microgrids.

Up to the present different centralized control strategies of microgrids have been proposed in the literature [28-30]. In [28], a control strategy for a DC microgrid was proposed. The strategy was aimed at minimizing the daily total energy costs. In [29], an optimization algorithm was applied to a group of interconnected MGs with the main grid. The procedures under study were charging/discharging of the ESS, starting or stopping the DGs, and receiving/sending power from/to neighboring MGs. In this case, the charge and discharge of the ESS relies on the energy demand and production. A centralized system for a DC distribution system was presented in [30]. The main objective of that control method was cost minimization based on the real-time electrical price. In order to meet that goal, converter control was based on voltage droop, which achieved the power sharing among the DGs and was responsible for tracking the DC bus voltage reference. In [31], a coordinated control strategy was addressed within a DC microgrid. In that case the converters were working as voltage sources. A virtual output resistance was implemented for each converter. However, no communications were implemented, which are necessary to optimize the power dispatch among the power converters and to restore the voltage deviations produced [14].

As it was described above, several centralized management and control strategies have been developed for DC microgrids. The strategies have been implemented by solving partial problems or using a particular control strategy. In this work, a centralized control technique for the efficient power 
management of an experimental DC microgrid is explained. The proposed DC microgrid is connected to the main grid through a bidirectional ILC (see Figure 1). The ILC is an AC/DC bidirectional converter which is responsible for managing the power flow between the DC bus and the main grid. The ILC regulates the DC bus voltage at a fixed value.

In this work, the MGCC does not account for the cost-effective operation of the system in terms of the energy tariffs. The MGCC receives information about the power exchange limits with the main grid from the grid operator. The power to be injected/extracted to/from the grid is calculated by an algorithm implemented in the MGCC starting from the knowledge of the PV available power, the load connected to the DC bus, the battery state and the power exchange limits provided by the grid operator. The goal of that algorithm is to import the needed power from the grid, keeping it below the established limits, feeding the loads and keeping the batteries $S o C$ inside a safe range. If a surplus of energy is available from the PV generation, power is injected to the grid below the limit imposed by the grid operator. No energy price considerations are taken into account by the implemented algorithm.

As shown in Figure 1, the DC microgrid consists of: (a) an MGCC; (b) an ILC connected to the main grid which controls the DC bus voltage; (c) two DC/DC converters that operate as a current source interchanging their power with the DC bus; (d) four loads with their respective electronic switches; (e) an RS-485 serial communication system and (e) the grid operator.

The main contribution of this paper is the integration of conventional control strategies of all the power converters in the microgrid by means of a centralized algorithm implemented in a MGCC, taking into account real time serial communications for sending/receiving the necessary data. An additional contribution of this work is the use of a realistic battery ESS control algorithm in the context of DC microgrids, which follows the charging procedure DIN 41773 [32,33]. Depending on their voltage, the batteries are charged either at a constant current or at a constant voltage. Once the current absorbed by the batteries is smaller than a pre-specified value of tail current, the battery voltage is kept at a certain float voltage. The integration of a load management algorithm, compatible with the microgrid status, is also described. The integration of all those strategies through an MGCC has not been reported by previous studies, to the best authors' knowledge. It is worth pointing out that most of previous studies for this kind of MG are theoretical, having been validated by simulation results $[4,28-31,34,35]$. In this paper, the experimental validation of the MGCC centralized algorithm in a DC microgrid is shown. It provides a realistic evaluation under different MG operation scenarios. Moreover, this work shows the MGCC algorithm runtime as well as the communication delays in order to ensure the stability of the DC bus.

Thus, the main objectives of the control strategies applied to the DC microgrid are the following:

- To comply with the power flow limits from/to the DC microgrid to/from the main grid. These limits are established by the grid operator and are set according to the purchase or sale tariffs of generated or consumed energy. This study takes into account the limit value of the power absorption/injection sent by the grid operator to the MGCC, as well as its effect on the general MG power management and on the power converters electrical behavior.

- To limit the photovoltaic power generation below the maximum available power if it is required. This limit depends on the power available in the DC bus and the power injection limit set by the grid operator.

- $\quad$ To develop the charging procedure DIN 41773 for Valve Regulated Lead-Acid (VRLA) [36] batteries of the ESS connected to the DC bus, in order to ensure the proper operation of the ESS and extend the life of its batteries.

- To manage the power demand of the devices connected to the DC bus by means of a load shedding functionality. This function, which is used only as a last resort, is applied according to the batteries status, the available power and a pre-established power threshold. The pre-established thresholds have a hysteresis level when connecting/disconnecting, avoiding destabilizing transients at the DC bus. 
- To control in real time the power flow inside the MG through RS485 serial communication. The proposed power management algorithm provides the optimal reference values, which are transmitted to each converter to establish their operation.

- To obtain smooth transients in the voltages and currents of the power converters connected in the DC bus, during the sudden changes of the power set points in each converter.

This paper is organized as follows: Section 2 describes the primary controls of every power converter of the DC microgrid. In Section 3, concepts related to the power management algorithm are explained. In Section 4, experimental and discussion results are presented. Finally, the conclusions are presented in Section 5.

\section{Description of the Power Electronic Converters Involved in the DC Microgrid}

The proposed DC microgrid is depicted in Figure 1. The interconnection between the DC bus and the PCC of the public grid is performed by a $10 \mathrm{~kW}$ bidirectional IC, which works in grid-connected mode. The $V_{\text {Grid }}=230 V_{\text {rms }}$ and its frequency is $F_{\text {Grid }}=50 \mathrm{~Hz} \pm 1 \mathrm{~Hz}$. The nominal DC bus voltage is $V_{D C}=380 \mathrm{~V}$, being regulated by the ILC [37]. In the MG under study, two converters are connected to the DC bus: the first one is a $3 \mathrm{~kW}$ bidirectional DC/DC converter connected to the batteries and the second one a $2.5 \mathrm{~kW}$ DC/DC converter connected to a PV array. The battery bank voltage $\left(V_{\text {Bat }}\right)$ of the ESS ranges from $194 \mathrm{~V}$ to $254 \mathrm{~V}$, whereas the voltages at the PV arrays $\left(V_{P V}\right)$ vary from $300 \mathrm{~V}$ to $370 \mathrm{~V}$. Additionally four 'shedable' $650 \mathrm{~W}$ DC loads are connected in the DC bus by means of individual electronic switches $\left(S_{w 1}\right.$ to $\left.S_{w 4}\right)$, that are controlled by the MGCC. It is important to highlight that the primary controllers of every converter are designed for satisfying demands of the MG; maintaining the stability in the DC bus voltage, battery bank and PV arrays. These control loops have a high bandwidth to ensure a fast response to changes in the current/voltage references [6]. Each power converter runs their corresponding inner primary controllers in a TMS320F28335 DSP. MGCC allows an exchange of information among different devices connected to the MG by means of the RS485 serial communication bus as is depicted in Figure 1. The parameters broadcasted through this bus among the power converters of the DC microgrid and the MGCC are shown in Table 1.

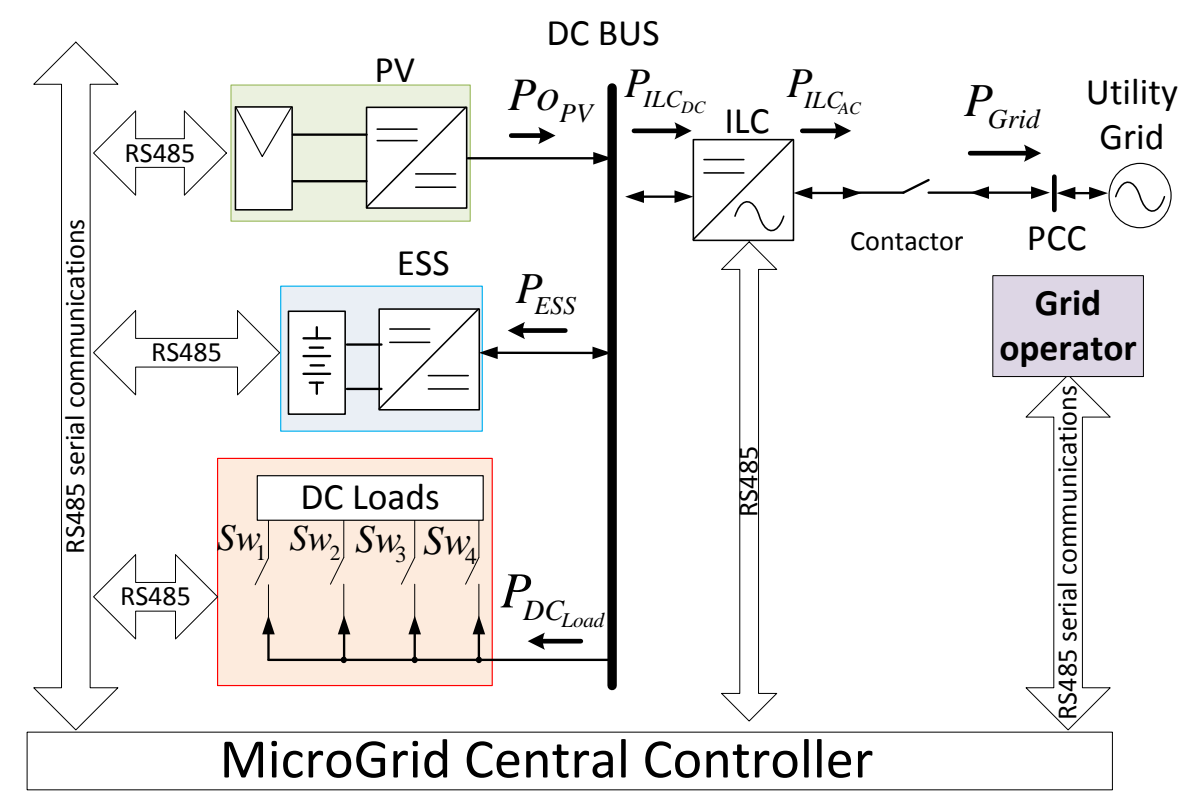

Figure 1. Conceptual scheme of the DC microgrid. 
Table 1. Parameters broadcasted between the power converters of the DC microgrid and the MGCC.

\begin{tabular}{ccccc}
\hline \multirow{2}{*}{ MGCC } & \multicolumn{5}{c}{ Power Converters } \\
\cline { 2 - 5 } & ILC & ESS & PV & DC Load \\
\hline Output setpoint & $V_{D C}{ }^{*}$ & $P_{E S S}{ }^{*}$ & $P_{P V_{-} L i m}{ }^{*}$ & $S=\left\{S_{w 1}{ }^{*}, S_{w 22}{ }^{*}, S_{w 3}{ }^{*}, S_{w 4}{ }^{*}\right\}$ \\
\hline Input measurement & $P_{I L C \_A C}$ & $P_{E S S}, S o C$ & $P O_{P V}$ & $P_{D C_{-} L o a d}$ \\
\hline \multicolumn{5}{c}{${ }^{*}$ MGCC references. }
\end{tabular}

\subsection{PV System}

The PV system consists of the PV arrays and a Boost DC/DC converter that is controlled as current source providing a certain amount of power to the DC bus (1):

$$
P o_{P V}=I_{P V} \cdot V_{P V} \cdot \eta_{P V}
$$

The PV system is shown in Figure 2a. An ISO5500 driver provides the isolation required between the PWM module of the DSP TMS320F28335 (Delfino Microcontroller, Texas Instruments Incorporated, Dallas, TX, USA) and the IGBTs (VS-GT50TP60N, Vishay Electronic GmbH, Selb, Germany). The control of the PV array voltage $\left(V_{P V}\right)$ has been implemented in cascade with the control of output current $\left(I_{L P V}\right)$ [7]. $G i_{P V}$ and $G v_{P V}$ blocks represent current and voltage regulators of the Boost DC/DC converter, respectively. These regulators are implemented by means of PI controllers, which are initialized to obtain soft transients in the following scenarios: (i) at the time of initial connection of the PV system to the DC bus, (ii) at sudden changes of irradiation and (iii) at sudden changes in the set point of PV power limit established by the MGCC $\left(P_{P V_{-} L i m}{ }^{*}\right)$. Thus, transient over-currents and over-voltages at the DC bus are avoided.
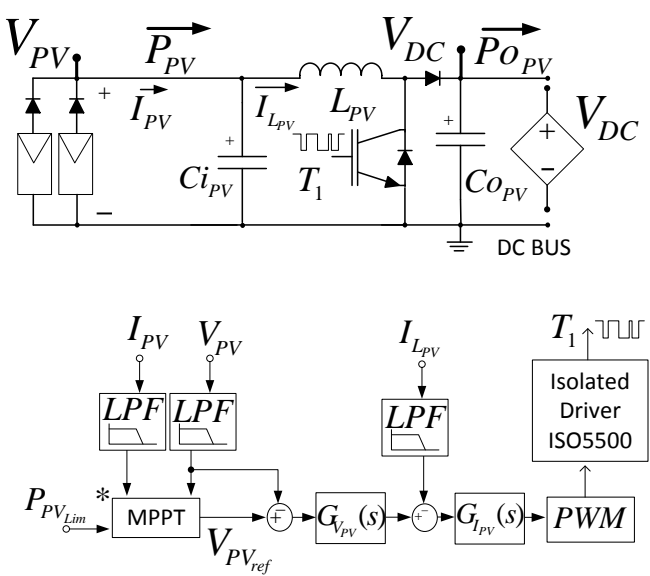

(a)

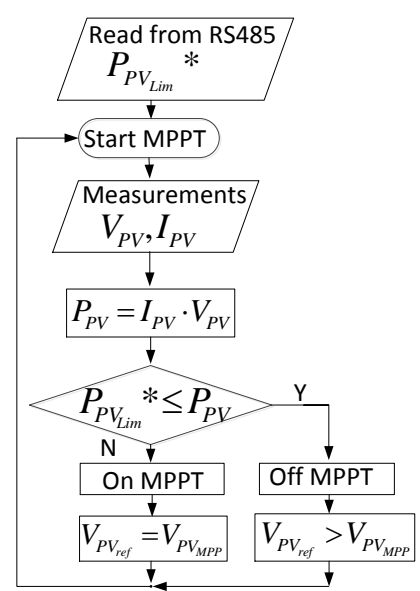

(b)

Figure 2. Topology and control of the PV system: (a) DC/DC converter; (b) Control strategy of the PV system.

The control strategy decision tree of the PV converter is depicted in Figure $2 \mathrm{~b} . P_{P V_{-} L i m}{ }^{*}$ is a reference power sent by the MGCC. The PV converter compares the available power in the PV array with the $P_{P V_{-} L i m}{ }^{*}$. If the available power at the PV array is lower than $P_{P V_{-} L i m}{ }^{*}$, the DC/DC will operate at the maximum power point (MPP) of the PV array, controlling $V_{P V}$ at the corresponding level. The Maximum Power Point Tracking (MPPT) algorithm sets the reference voltage $\left(V_{P V_{-} r e f}\right)$ to $V_{P V_{-} \text {ref }}=V_{P V_{-} M P P}$ and the PV source works at its MPP (On MPPT). Otherwise, in order to limit the PV power injected to the DC bus to $P_{P V_{-} L i m}{ }^{*}$, the MPPT sets $V_{P V_{-} r e f}$ at a voltage higher than $V_{P V_{-} M P P}$, so that the PV array can be operated outside its MPP (Off MPPT). 


\subsection{Energy Storage System (ESS)}

The ESS keeps the power balance of the DC bus [38,39] and consists of the battery bank and a $3 \mathrm{~kW}$ half-bridge DC/DC converter (see Figure 3a). The ESS is controlled as current source, absorbing a certain amount of power from the DC bus. $P_{E S S}$ is the power at which the battery ESS is charged, which is measured in real time. That power is calculated following Equation (2):

$$
P_{E S S}=I_{B a t} \cdot V_{B a t} \cdot \eta_{E S S}
$$

It is worth pointing out that $P_{E S S}$ is negative if the power is injected to the DC bus from the ESS. The battery bank of the ESS is designed to deliver up to $3 \mathrm{~kW}$. The battery bank it is composed of 18 batteries of $12 \mathrm{~V}$ connected in series, with a nominal voltage of $V_{B a t}=216 \mathrm{~V}$ and a charging voltage of $V_{B a t(C h)}=254 \mathrm{~V}$. VRLA model SUN POWER VRM 12V105 batteries (HOPPECKE, Brilon, Germany) for cyclic applications were selected,. The characteristics of the ESS are shown in Table 2. The control loops of the ESS are also represented in Figure 3a. The control of the battery bank voltage $\left(V_{B a t}\right)$ has been implemented in cascade with the output current controller $\left(I_{L B a t}\right)$. G $v_{\text {Bat }}$ and $G i_{\text {llbat }}$ blocks represent the voltage and current regulators of the DC/DC converter, respectively. These regulators are PI controllers, which are adjusted and initialized to obtain soft transients for any sudden change of the power reference $P_{E S S}{ }^{*}$ sent by the MGCC.

The battery management algorithm is depicted in Figure $3 \mathrm{~b}$. The setpoint $P_{E S S} *$ is the power available at the DC bus for charging the batteries, which is calculated by the MGCC. $P_{E S S}{ }^{*}$ is sent by the MGCC to the ESS. The ESS reads $P_{E S S}$ * and changes the signal 'Mode' depending on $P_{E S S}$ *. 'Mode' is a flag that takes two possible states. If $P_{E S S}{ }^{*}>0$, the signal 'Mode' takes a high value, 'Mode $=1$ ' (supply mode). On the contrary, if $P_{E S S}{ }^{*}<0$ the signal 'Mode' takes a low value, 'Mode $=0$ ' (charge mode). The ESS performs soft power transitions to avoid fluctuations of the DC bus voltage by means of avoiding abrupt bidirectional changes in the signal $P_{E S S}{ }^{*}$, see Figure $3 c . P_{E S S_{-} r e f}$ is the power reference for the DC/DC control and it is changed progressively from an initial value $P_{\text {ESS_initial }}$ * to a final value $P_{E S S}{ }^{*}$ according to a ramp function with a $100 \mathrm{~ms}$ duration. The ramp function produces a variation of $P_{E S S_{-} \text {ref }}$ between the values $P_{\text {ESS_initial }}$ * and $P_{E S S} *$ in a time of $100 \mathrm{~ms}$, with an update period of $\triangle t_{R A M P}=1 \mathrm{~ms}$. The ramp function and $P_{E S S_{-} \text {ref }}$ are shown by Equations (3) and (4), respectively:

$$
\begin{aligned}
r(t) & =\frac{t}{100 \cdot \Delta t_{\text {RAMP }}},(0 \leq t \leq 100 \mathrm{~ms}) \\
P_{E S S_{\text {ref }}} & =P_{E S S_{\text {initial }}}+\left(P_{E S S} *-P_{E S S_{\text {initial }}}\right) \cdot r(t)
\end{aligned}
$$

The battery management algorithm guarantees suitable voltage levels and charging/discharging currents. Thus, both the overheating and the damage of the batteries are avoided. The charging process follows the DIN 41773 (IU curve), see Figure 3d. Depending on their voltage, the batteries are charged either at a constant current or at a constant voltage. Once the current absorbed by the batteries is smaller than a pre-specified value of tail current $\left(I_{\text {bat_tail }}\right)$ or a charging time $\left(t_{C h}\right)$, the battery voltage is kept at a certain float voltage $\left(V_{\text {bat_float }}\right)$. The signal ' $C C$ ' is a flag that identifies the charge mode. If ' $C C=1$ ' it means that the batteries are being charged at a constant current (constant current mode), whereas if ' $C C=0$ ' the batteries are being charged at a constant voltage (constant voltage mode).

The ESS sends the state of charge $(S o C)$ of the battery bank to the MGCC in order to obtain the highest possible performance [39-41]. In Figure 3a, $\mathrm{SoC}$ is calculated from Equation (5) where: $C_{T}$ is the total capacity of the battery bank (A.h), $C_{D i s}$ is the discharge capacity in A.h, and $\eta_{D i s}$ is the discharge efficiency. The reference of the battery charge current $\left(I_{C h \_r e f}\right)$ is calculated from Equation (6); whereas the discharge current ones $\left(I_{\text {Dis_ref }}\right)$ is calculated from Equation (7). Parameter $P_{E S S C 10}$ is the maximum power for discharging the batteries of the ESS. It has been established that the batteries are charged with a current equal to $I_{C 10}=C_{10} / 10 \mathrm{~h}$, being $C_{10}$ the specified battery capacity (measured in A.h) for a discharge time of $10 \mathrm{~h} . P_{E S S C 10}=V_{B a t} \cdot I_{C 10} / \eta_{E S S}$, where $\eta_{E S S}$ is the ESS efficiency: 


$$
\begin{gathered}
\operatorname{SoC}(t)=\operatorname{SoC}(0)-\eta \cdot \int_{0}^{t} \frac{I_{D i s}(t)}{C_{T}} \cdot d t \\
\eta_{D i s}=\frac{C_{D i s}}{C_{T}} \\
I_{C h_{\text {ref }}}=\operatorname{MIN}\left(\frac{P_{E S S C 10}}{V_{B a t}}, \frac{P_{E S S_{\text {ref }} \cdot \eta_{E S S}}}{V_{\text {Bat }}}\right) \text { where } P_{E S S_{\text {ref }}}>0 \\
I_{D i s_{\text {ref }}}=-\operatorname{MIN}\left(\frac{P_{E S S C 10}}{V_{\text {Bat }}},\left|\frac{P_{E S S_{r e f}} \cdot \eta_{E S S}}{V_{\text {Bat }}}\right|\right) \text { where } P_{E S S_{r e f}}<0
\end{gathered}
$$

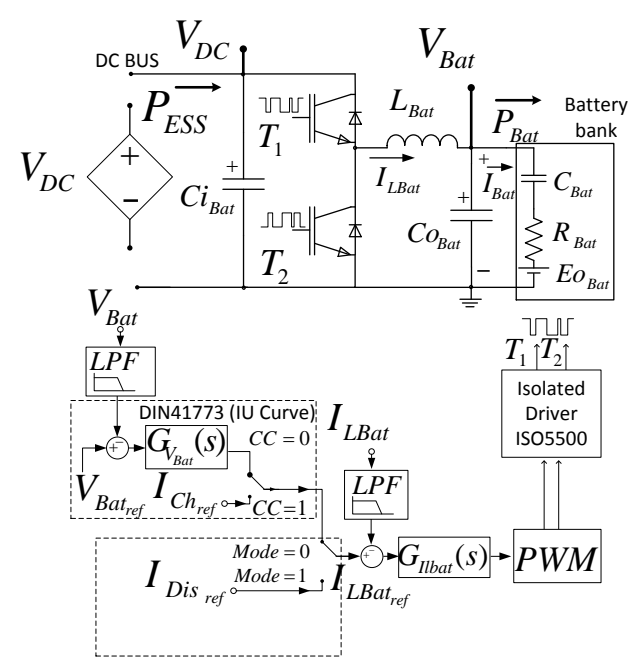

(a)

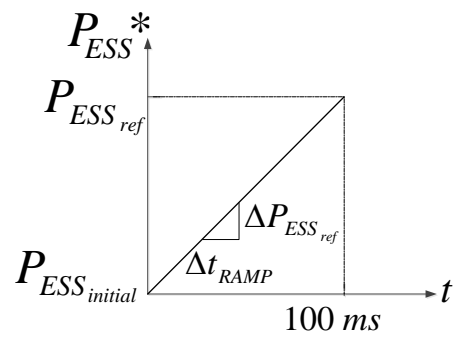

(c)

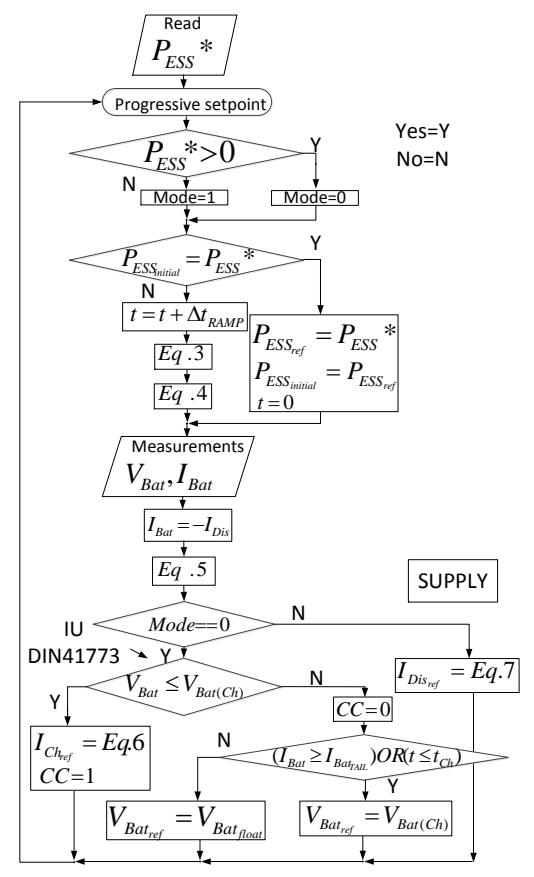

(b)

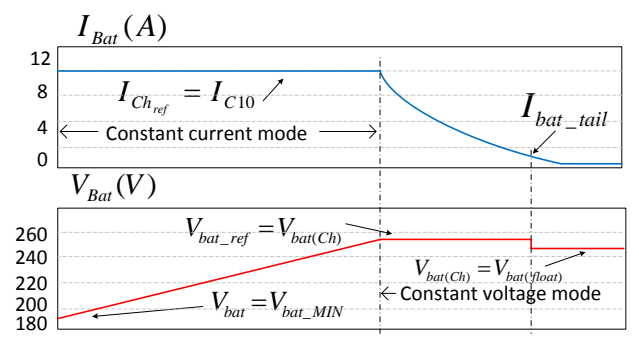

(d)

Figure 3. Topology and control of the ESS: (a) Half-bridge DC/DC converter; (b) Proposed battery charging/discharging control algorithm; (c) Ramp function; (d) DIN 41773 (IU curve).

Table 2. Characteristics of the ESS.

\begin{tabular}{ccc}
\hline \multirow{2}{*}{ DC/DC Converter } & Battery Specifications & DIN 41773 \\
\cline { 2 - 3 } & SUN POWER VRM 12V105 & Battery Bank 18 Batteries Connected in Series \\
\hline$P_{E S S \_H B}=3 \mathrm{~kW}$ & $V_{\text {rated }}=12 \mathrm{~V}$ & $V_{\text {Bat_rated }}=216 \mathrm{~V}$ \\
$F_{\text {Sw_ESS }}=16 \mathrm{kHz}$ & $V_{M I N}=10.28 \mathrm{~V}$ & $V_{\text {Bat }(\text { Ch })}=254 \mathrm{~V}$ \\
$C_{\text {iBat }}=1 \mathrm{mF}$ & $C_{T}=105 \mathrm{~A} \cdot \mathrm{h}$ & $V_{\text {bat_float }}=243 \mathrm{~V}$ \\
$C_{\text {oBat }}=1 \mathrm{mF}$ & $C_{100}=101 \mathrm{~A} \cdot \mathrm{h}$ & $V_{\text {Bat_MIN }}=194 \mathrm{~V}$ \\
$L_{\text {Bat }}=5.4 \mathrm{mH}$ & $C_{10}=87 \mathrm{~A} \cdot \mathrm{h}$ & $I_{C 10}=8.7 \mathrm{~A}$ \\
$I_{\text {Lbat_max }}=12 \mathrm{~A}$ & $\eta_{C 10}=0.83$ & $I_{\text {bat_tail }}=0.5 \mathrm{~A}$ \\
$\eta_{E S S}=0.97$ & $\eta_{C 100}=0.96$ & $t_{C h}<48 \mathrm{~h}$ \\
\hline
\end{tabular}




\subsection{Interlinking Converter}

Figure 4 depicts the single-phase ILC implemented. The power stage is a full-bridge (bidirectional) inverter, which interconnects the DC bus and the grid. The ILC is controlled as a current source (ILC_AC) injecting/extracting a power to/from the main grid synchronously with the grid [42]. If the power flows from the grid to MG, it results: $P_{\text {Grid }}<0$ and $\left|P_{I L C_{A C}}\right|=\left|P_{\text {Grid }}\right|$. Otherwise, when the power flows from the MG to the grid, it results: $P_{\text {Grid }}>0$ and $P_{I L C_{-} A C}=P_{\text {Grid }} . P_{I L C_{-} A C}$ stands for the power injected by the ILC to the grid. The DC bus voltage is controlled by the ILC, which is possible in grid-connected mode, as can be seen in Figure 4. The nominal DC bus voltage is $380 \mathrm{~V}$, as it's the current trend in domestic and industrial DC microgrids [43]. The grid voltage $\left(V_{G r i d}\right)$ is measured by a phase locked loop (PLL) [44] programmed inside the ILC DSP controller, which detects the grid phase $(\varphi)$ and its frequency $(\omega)$. $G i_{I L C}(s)$ and $G v_{I L C}(s)$ blocks represent, respectively, the transfer functions of the current and voltage regulators of the ILC, having the following characteristics:

- $G i_{I L C}(s)$ consists of a proportional regulator working in parallel with four resonant controllers tuned at frequencies: $\omega, 3 \omega, 5 \omega$ and $7 \omega$, being $\omega$ the grid angular frequency (Equation (8)). Those resonant controllers are known as second order generalized integrators (SOGIs) [42], which provide a high gain at the grid frequency and at some of its odd non-triplen multiples. If a variation of the frequency of the grid takes place, the SOGIs center frequencies vary correspondingly.

- $G v_{I L C}(s)$ consists of a Notch filter operating in series with a PI controller (Equation (9)). The notch filter removes the second harmonic of the grid fundamental frequency present at the DC bus voltage from the reference signal of the current controller:

$$
\begin{gathered}
G i_{I L C}(s)=0.035+\sum_{i=1,3,5,7} \frac{40}{i} \cdot \frac{0.001 \cdot(i \cdot \omega) \cdot s}{s^{2}+0.001 \cdot(i \cdot \omega) \cdot s+(i \cdot \omega)^{2}} \\
G v_{I L C}(s)=-0.1178 \cdot \frac{1+0.46 \cdot s}{0.46 \cdot s} \cdot \frac{s^{2}+(2 \cdot \omega)^{2}}{s^{2}+(2 \cdot \omega) \cdot s+(2 \cdot \omega)^{2}}
\end{gathered}
$$

The controllers of the ILC keep the total harmonic distortion (THDi) of the current injected/absorbed to/from the grid within the limits of the IEEE1547 standard [45].

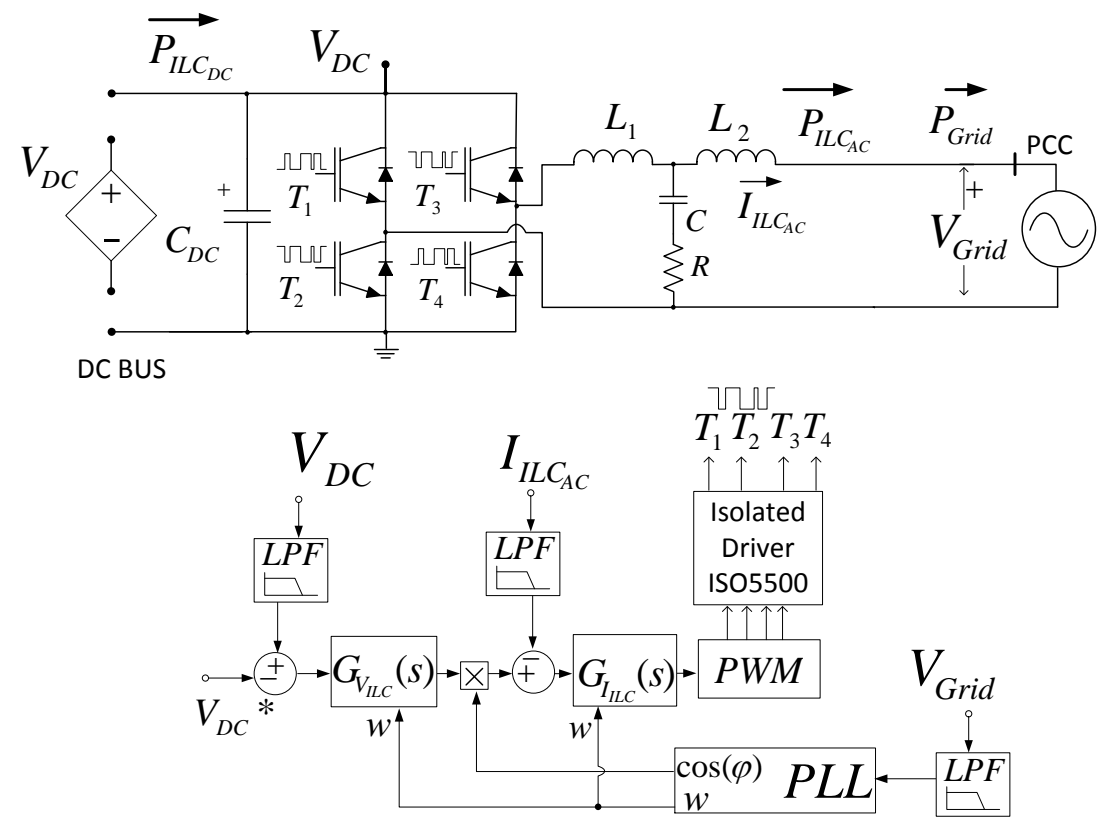

Figure 4. Topology and control diagram of the ILC. 


\subsection{Electronic Switches}

The MGCC controls the load demand at the DC bus by connecting/disconnecting up to four loads to/from the DC-bus using of individual switches, as it can be observed in Figure 5. The sets of electronic switches are $S_{w 1}, S_{w 2}, S_{w 3}, S_{w 4}$. The control signals sent by the MGCC are represented by $S_{w(i)} *=\left\{S_{w 1} * S_{w 2} * S_{w 3} *, S_{w 4} *\right\} . S_{w} *$ is a vector where every of its elements are binary variables $\{0,1\}$, indicating which loads are connected $\{1\}$ or disconnected $\{0\}$. An ISO5500 driver provides the isolation required between the control circuitry implemented around a TMS320F28335 DSP and the IGBT-diodes bidirectional electronic switches. Four electronic switches control the shed-able DC loads remotely by means of RS485 communication implemented in the DSP. The DSP gets the measurements of the overall load current $\left(I_{D C L o a d}\right)$ and of the DC bus voltage and computes the overall DC load power consumption, $P_{D C_{-} \text {Load }}$. $P_{D C_{-} \text {Load }}$ can be expressed by Equation (10):

$$
P_{D C_{\text {Load }}}=V_{D C} \cdot \sum_{i=1}^{4} I_{D C_{\text {Load }(i)}} \cdot S_{w(i)}{ }^{*}
$$

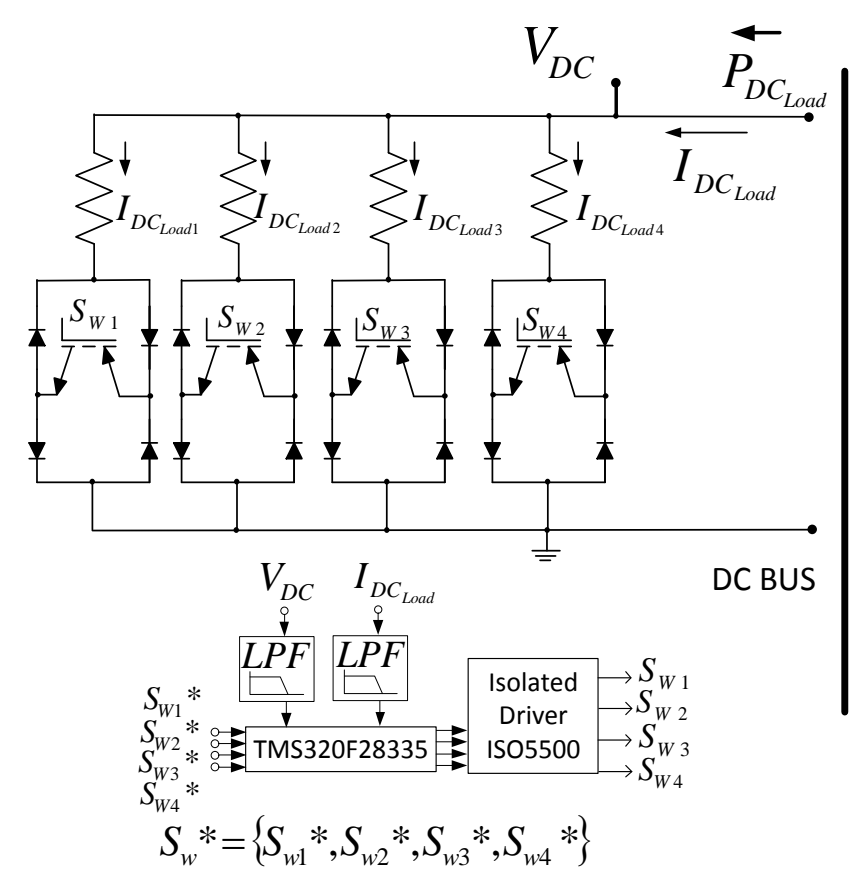

Figure 5. Topology of the electronics switches.

\section{Management and Control of the DC Microgrid}

In this section, several concepts and parameters of the MGCC are explained, in order to define the DC microgrid features, control and functionalities for the efficient application of the proposed algorithm.

\subsection{Grid Operator Power Limits}

The main grid operator establishes a tertiary high-level control strategy that manages the power flow between the DC microgrid and the grid. The grid operator imposes a limit of the power injected from the DC microgrid to the grid or vice versa. The power flow scenarios between the grid and the DC microgrid are shown in Figure 6. Two general cases are possible: $P_{\text {Grid }}<0$ and $P_{\text {Grid }}>0$. 


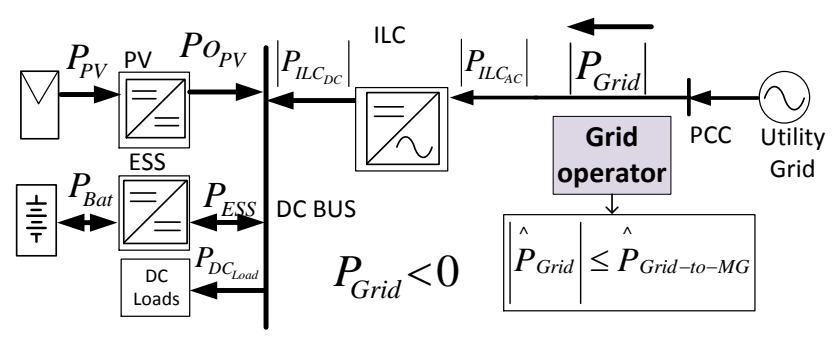

(a)

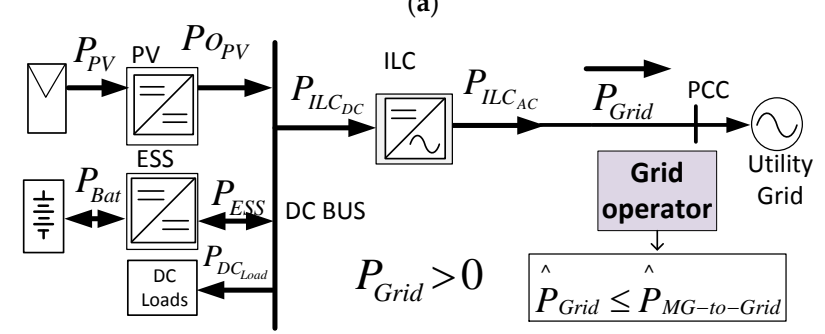

(b)

Figure 6. The power flow scenarios between the grid and the DC microgrid: (a) Power flow from the grid to the DC microgrid $\left(P_{\text {Grid }}<0\right)$; (b) Power flow from the DC microgrid to the grid $\left(P_{\text {Grid }}>0\right)$.

\subsubsection{Maximum Power Extracted from the Grid}

The power flow from the grid to the DC microgrid is shown in Figure 6a. Parameter $\hat{P}_{\text {Grid-to-MG }}$ is established by the grid operator, standing for the maximum power that can be extracted from the main grid to the DC microgrid, imposing Condition (11):

$$
\left|P_{\text {Grid }}\right| \leq \hat{P}_{\text {Grid-to-MG }}
$$

\subsubsection{Maximum Power Injected to the Grid}

The power flow from the DC microgrid to the grid is shown in Figure $6 \mathrm{~b}$. Parameter $\hat{P}_{M G-t o-G r i d}$ stands for the maximum power that can be injected from the DC microgrid to the main grid. This parameter is established by the grid operator, imposing Condition (12):

$$
P_{\text {Grid }} \leq \hat{P}_{M G-t o-G r i d} .
$$

\subsection{MG Central Controller}

The MGCC establishes some parameters for the secondary control strategy, which is responsible for the power flow between the grid and the DC microgrid.

\subsubsection{Power Flow Limits between the MG and the Grid}

Equation (13) stands for the maximum power which can be extracted from the grid to the DC bus, measured at the AC side of the ILC. In (14) is represented the maximum absolute value of $P_{I L C} A C$ must meet condition at any time, taking into account the rated power of the ILC, $P_{I L C}$ AC-Rated. In this study: $P_{\text {ILC AC-Rated }}=10 \mathrm{~kW}$ :

$$
\begin{gathered}
\left.\hat{P}_{I L C_{A C}}\right|_{\text {Grid-to-MG }}=\hat{P}_{\text {Grid-to-MG }} \\
\left|\hat{P}_{I L C_{A C}}\right| \leq M I N\left(\left.P_{I L C_{A C-R a t e d},} \hat{P}_{I L C_{A C}}\right|_{\text {Grid-to-MG }}\right)
\end{gathered}
$$

Equation (15) stands for the maximum power which can be injected from the DC bus to the grid, measured at the AC side of the ILC. The maximum power injected from the DC bus to the grid by the ILC at any time is defined by (16):

$$
\left.\hat{P}_{I L C_{A C}}\right|_{M G-t o-G r i d}=\hat{P}_{M G-t o-G r i d}
$$




$$
\hat{P}_{I L C_{A C}} \leq \operatorname{MIN}\left(P_{I L C_{A C-R a t e d}},\left.\hat{P}_{I L C_{A C}}\right|_{M G-t o-G r i d}\right)
$$

\subsubsection{Power Comparison Parameters}

Equation (17) gives the available PV power plus the maximum power that can be transferred from the grid to the DC bus by the ILC, where $\eta_{I L C}$ is the ILC efficiency:

$$
P_{D C-B U S}=P o_{P V}+\frac{\left.\hat{P}_{I L C_{A C}}\right|_{G r i d-t o-M G}}{\eta_{I L C}}
$$

Equation (18) is the extra power available both from the PV DG connected to the DC bus and from the grid coming through the ILC, after feeding the load connected to the DC bus. The powers consumed by the loads connected to the DC bus is $P_{D C_{-} \text {Load }}$. $D C_{\text {Load_hyst }}$ is a hysteresis threshold used for performing the comparison between the available power level and the power required by the load. The comparison is performed with a certain hysteresis, so that erratic connections/disconnections of the load are avoided when the available power and the required power are very close each other. The value of $D C_{\text {Load_hyst }}$ is $10 \%$ of the power consumed by the DC loads:

$$
P_{\text {Available }_{D C}}=P_{D C-B U S}-P_{D C \text { Load }}-D C_{\text {Load }_{\text {hys }}}
$$

\subsubsection{Power Control Parameters}

Parameter $P_{P V_{-} L i m}{ }^{*}$ is the maximum power that should be extracted from the PV sources at any time, therefore it can be consumed by the DC loads and by the batteries and/or it can be injected to the grid. $P_{P V \_L i m}{ }^{*}$ is represented by (19). $\hat{P}_{D C \text { Load }}$ stands for the maximum overall power consumed by the DC loads without applying the load shedding functionality:

$$
P_{P V_{\text {Lim }}}{ }^{*}=\frac{\left.\hat{P}_{I L C_{A C}}\right|_{M G-\text { to-Grid }}}{\eta_{I L C}}+\hat{P}_{D C \text { Load }}+P_{E S S}
$$

The ESS has two possible modes, supply mode and charge mode, depending on the available power at the DC bus and the $S o C$ of the battery bank. The $S o C$ is kept between the following values: So $C_{\text {MIN }}=20 \%$ and SoC Full $=100 \%$.

In charge mode, the ESS absorbs power from the DC bus to charge the battery bank. ESS gets the power reference from the MGCC, which it is calculated as in (20). ESS charges the batteries until $S_{0} C_{\text {Ready }} \leq S o C \leq S o C_{\text {Full }}$, being $S o C_{\text {Ready }}=80 \%$.

In supply mode, the ESS injects power from the battery bank to the DC bus and can be activated if $S o C \geq S o C_{\text {Ready }}$. The ESS gets the power reference from the MGCC, which it is calculated as in (21):

$$
\begin{gathered}
P_{E S S}{ }^{*}=\operatorname{MIN}\left(\text { PESS }_{C 10}, P_{D C-B U S}-P_{D C \text { Load }}\right) \\
P_{E S S}{ }^{*}=-\operatorname{MIN}\left(P E S S_{C 10},\left|P_{D C-B U S}-P_{D C \text { Load }}\right|\right)
\end{gathered}
$$

\subsubsection{Power Management Algorithm of the DC Microgrid}

Figure 7a depicts the flowchart of the proposed power management algorithm. The MGCC requests power information of all the MG elements and the $S o C$ of the batteries, which is used to estimate the power references of each converter, that are broadcasted to establish the power flows required in the MG. The DC load switch (Sw) is a flag that takes two possible states $S w=$ On and $S w=$ Off, depending on the connection or disconnection of loads to the DC bus, respectively. The load shedding functionality can be observed in the Figure $7 \mathrm{~b}$, which depicts how one to four DC-loads are connected-disconnected as a function of the value of Equation (18). The load shedding functionality decides on their disconnection if Equation (18) is not enough to energize all the DC loads. 


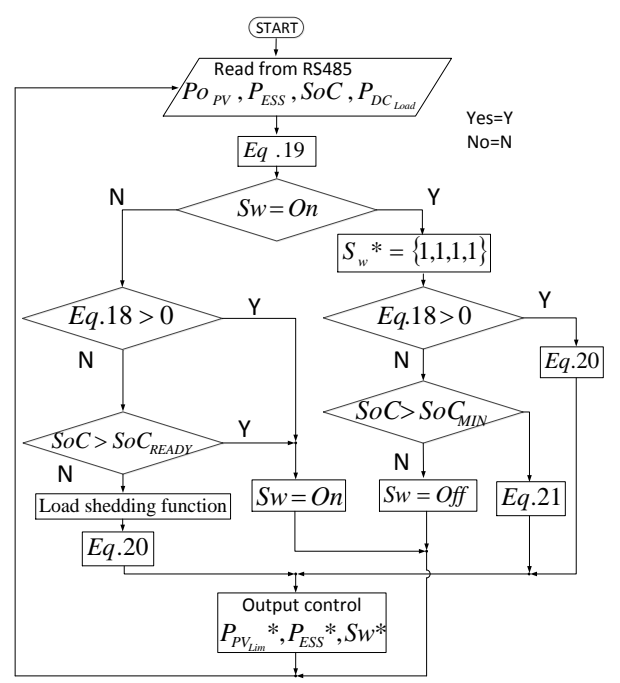

(a)

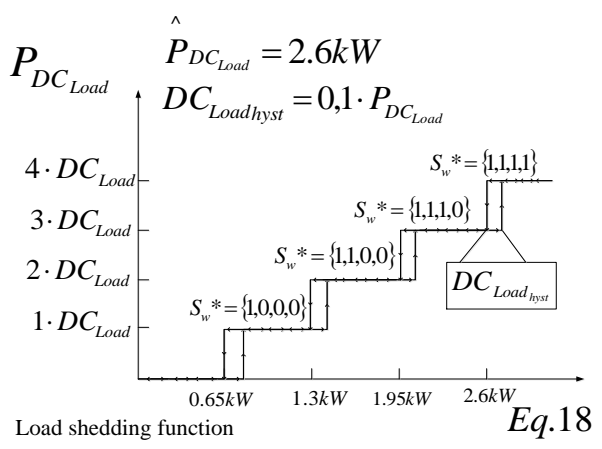

(b)

Figure 7. MGCC: (a) Power management algorithm of the DC microgrid; (b) Load shedding functionality.

\section{Experimental Results and Discussion}

Several experimental power electronic converters have been built for validating the power management strategies devised in this study. The power converters and PV panel specifications are shown in the Table 3. The following devices have been connected to the DC bus of the MG available in the lab: a $3 \mathrm{~kW}$ battery ESS, a $2.5 \mathrm{~kW}$ PV source and four electronic switches to connect/disconnect four DC loads of $650 \mathrm{~W}$ each one. The connection of the DC bus and the grid is performed by a single-phase ILC of $10 \mathrm{~kW}$ that works in grid-connected mode. Figure 8a,b show the schematic diagram and a picture of the experimental DC microgrid, respectively. The batteries have been emulated by a bidirectional DC source/battery emulator model TC.GSS-Bidirectional-DC-PSU from Regatron AG (Rorschach, Switzerland). The PV array has been emulated by means of a $10 \mathrm{~kW}$ PV array simulator TerraSAS ETS1000/10 from Ametek (San Diego, CA, USA). The LabView software (National Instruments Spain, Madrid, Spain) is used for emulated the grid operator, for the initializing/stopping sequence and the monitoring the power dispatch of the DC microgrid. Several scenarios have been studied in order to demonstrate the suitable behavior of the DC microgrid in its most common and critical situations. In the scenarios under study step changes of the irradiation, DC load, SoC and power limits have been considered, as it can be observed in the following graphics.

Table 3. Characteristics of the power converters composing the DC microgrid.

\begin{tabular}{|c|c|c|}
\hline ILC & ESS & PV \\
\hline$P_{I L C}=10 \mathrm{~kW}$ & $P_{E S S_{H} H B}=3 \mathrm{~kW}$ & $P_{P V_{-} \text {Boost }}=2.5 \mathrm{~kW}$ \\
\hline$V_{\text {Grid }}=230 \mathrm{~V}$ & $V_{\text {Bat }}=216 \mathrm{~V}$ & $V_{P V}=306 \mathrm{~V}$ \\
\hline$F_{\text {Grid }}=50 \mathrm{~Hz}$ & $F_{S w_{-} E S S}=16 \mathrm{kHz}$ & $F_{s w_{-} P V}=16 \mathrm{kHz}$ \\
\hline$V_{D C}=380 \mathrm{~V}$ & $C_{i B a t}=1 \mathrm{mF}$ & $C_{O P V}=1 \mathrm{mF}$ \\
\hline$F_{S w_{-} I L C}=12.8 \mathrm{kHz}$ & $C_{o \text { Bat }}=1 \mathrm{mF}$ & $C_{i P V}=1 \mathrm{mF}$ \\
\hline $\bar{C}_{D C}=3.8 \mathrm{mF}$ & $\begin{aligned} L_{\text {Bat }} & =5.4 \mathrm{mH}\end{aligned}$ & $L_{P V}=5.4 \mathrm{mH}$ \\
\hline$L_{1}=1.2 \mathrm{mH}$ & $\begin{array}{l}\text { Battery Bank: } 18 \text { batteries type SUN POWER VRM } \\
\text { 12V105 connected in series }\end{array}$ & PV Panel: Atersa A-250P GSE \\
\hline$L_{2}=0.4 \mathrm{mH}$ & - & $V_{P V o c}=37.01 \mathrm{~V}$ \\
\hline$C=2 \mu \mathrm{F}$ & - & $I_{P V \_M A X}=8.18 \mathrm{~A}$ \\
\hline$C_{D C}=3.8 \mathrm{mF}$ & - & $V_{P V M A X}=30.58 \mathrm{~V}$ \\
\hline- & - & $I_{P V_{-} C C}=8.71 \mathrm{~A}$ \\
\hline \multicolumn{3}{|c|}{ Power dispatch limits established by the grid operator } \\
\hline \multicolumn{2}{|c|}{$\hat{P}_{M G-t o-G r i d}=4 \mathrm{~kW}$} & $t o-M G=1 \mathrm{~kW}$ \\
\hline
\end{tabular}

Interval $1.2(38 \mathrm{~s}<t<41 \mathrm{~s})$ : The irradiation increases from $100 \mathrm{~W} / \mathrm{m}^{2}$ to $800 \mathrm{~W} / \mathrm{m}^{2}$ in $3 \mathrm{~s}$. 


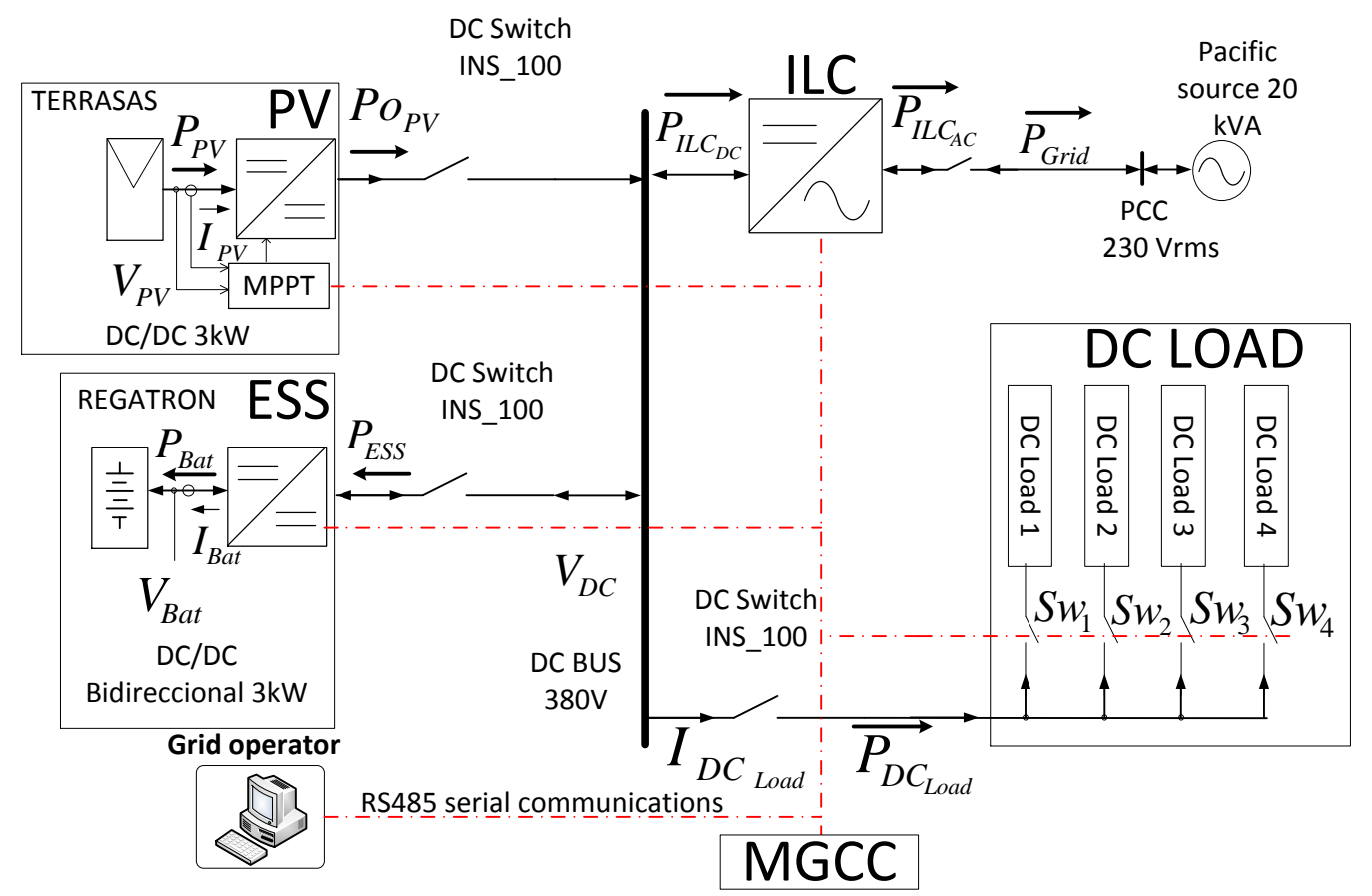

(a)

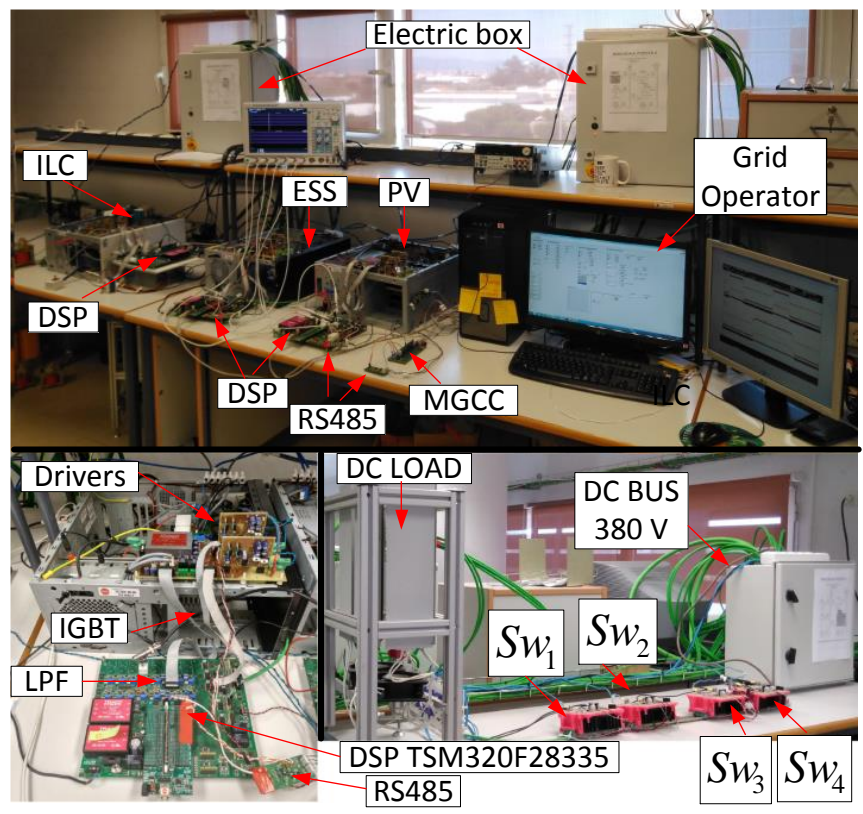

(b)

Figure 8. Experimental MG: (a) Schematic diagram of the experimental DC microgrid (b) Picture of the experimental DC microgrid.

Four experiments have been carried out. Figures 9-11 depict the waveforms of the currents, voltages and powers of the power converters composing the DC bus of the MG corresponding to experiments \#1 to \#3, respectively. Figure 12 corresponds to experiment \#4 and depicts the waveforms and delays of the communication system of the MG. Experiments \#1 to \#3 show the behavior of the system with the same change of the irradiation level at the PV source, except with a different $\mathrm{SoC}$ of the ESS. The power dispatch limits established by the grid operator from the grid to the DC bus by the ILC is $P_{I L C \_D C}=-1 \mathrm{~kW}$ in all the experiments. The hysteresis level for comparisons is: $D C_{\text {Load_hyst }}=260 \mathrm{~W}$. 


\subsection{Experiment \#1}

The ESS is initially at a $S o C \geq S o C_{M I N}$. In Figure 9 can be observed that four loads keep connected during the whole experiment, $\left(P_{D C_{-} \text {Load }}=2.6 \mathrm{~kW}\right)$. Two zoom images can be observed in the lower plot from Figure 9. In Zoom 1, it is shown the detection by the MGCC of an increase in PV system generation. In Zoom 2 it is shown the detection of a decrease in PV system generation. The analysis is performed according to the following time intervals:

Interval $1.1(0 \mathrm{~s}<t<38 \mathrm{~s})$ : The irradiation level is $100 \mathrm{~W} / \mathrm{m}^{2}$ and the PV source works at its MPP, providing $P_{P V}=230 \mathrm{~W}$ to the DC bus. That irradiation is not enough to feed all the DC loads. Taking into account that the ESS is charged ( $S o C \geq 50 \%$ ) the MGCC transfers the maximum possible power from the grid $\left(P_{I L C} D C=-1 \mathrm{~kW}\right)$ to the DC bus through the ILC. MGCC keeps all the DC loads connected and orders the ESS deliveries all the power required by the DC bus, $P_{B a t}=-1.4 \mathrm{~kW}$. See Figure 9.

In Zoom 1 of the Figure 9, at $t=38.5 \mathrm{~s}$; MGCC detects an increase of PV system generation, the PV source works at its MPP delivering $P_{P V}=0.4 \mathrm{~kW}$. The MGCC transfers the maximum possible power from the grid $\left(P_{I L C} D C=-1 \mathrm{~kW}\right)$, and keeps all the DC loads connected $\left(P_{D C_{-} L o a d}=2.6 \mathrm{~kW}\right)$. ESS supplies all the power required by the DC bus, the power delivered by the ESS is reduced to $P_{\text {Bat }}=-1.2 \mathrm{~kW}$.

At $t=39.9 \mathrm{~s}$; MGCC detects increasing generation, the PV source works at its MPP delivering $P_{P V}=1.2 \mathrm{~kW}$. The MGCC transfers the maximum possible power from the grid $\left(P_{I L C_{-} D C}=-1 \mathrm{~kW}\right)$, and keeps all the DC loads connected $\left(P_{D C_{-} \text {Load }}=2.6 \mathrm{~kW}\right)$. ESS supplies all the power required by the DC bus, the power delivered by the ESS is reduced to $P_{\text {Bat }}=-0.4 \mathrm{~kW}$.

At $t=41 \mathrm{~s}$ the PV source works at its MPP delivering $P_{P V}=1.85 \mathrm{~kW}$, being $P_{I L C} D D C=-1 \mathrm{~kW}$. At that instant the MGCC detects that the available power at the DC bus to feed all the DC loads is higher than the hysteresis level (Equation $(18) \geq 0$ ).

Interval $1.3(41 \mathrm{~s}<t<70.5 \mathrm{~s})$ : The irradiation level is $800 \mathrm{~W} / \mathrm{m}^{2}$ and the PV source works at its MPP, providing $P_{P V}=1.85 \mathrm{~kW}$ to the DC bus. The MGCC forces the ESS to change its operation to energy storage mode, the batteries are charged with a current given by (6). The ESS changes the setpoint $I_{C h \_r e f}$, until the available power is stable (At $t=42 \mathrm{~s}, P_{B a t}=0.2 \mathrm{~kW}$ ).

Interval $1.4(70.5 \mathrm{~s}<t<75.5 \mathrm{~s})$ : The irradiation decreases from $800 \mathrm{~W} / \mathrm{m}^{2}$ to $100 \mathrm{~W} / \mathrm{m}^{2}$ in $3 \mathrm{~s}$. See Zoom 2 of the Figure 9.

At $t=72.8 \mathrm{~s}$ the PV source works at its MPP, providing $P_{P V}=0.82 \mathrm{~kW}$ to the DC bus. Taking into account that the ESS is charged $(\mathrm{SoC}>50 \%)$. The MGCC forces the ESS to change its operation to supply mode, the batteries are discharged with a current given by Equation (7). The ESS changes the setpoint $I_{\text {Dis_ref, }}$ until the available power generation is stable (At $t>74.5 \mathrm{~s}, P_{\text {Bat }}=-1.4 \mathrm{~kW}$ ). 


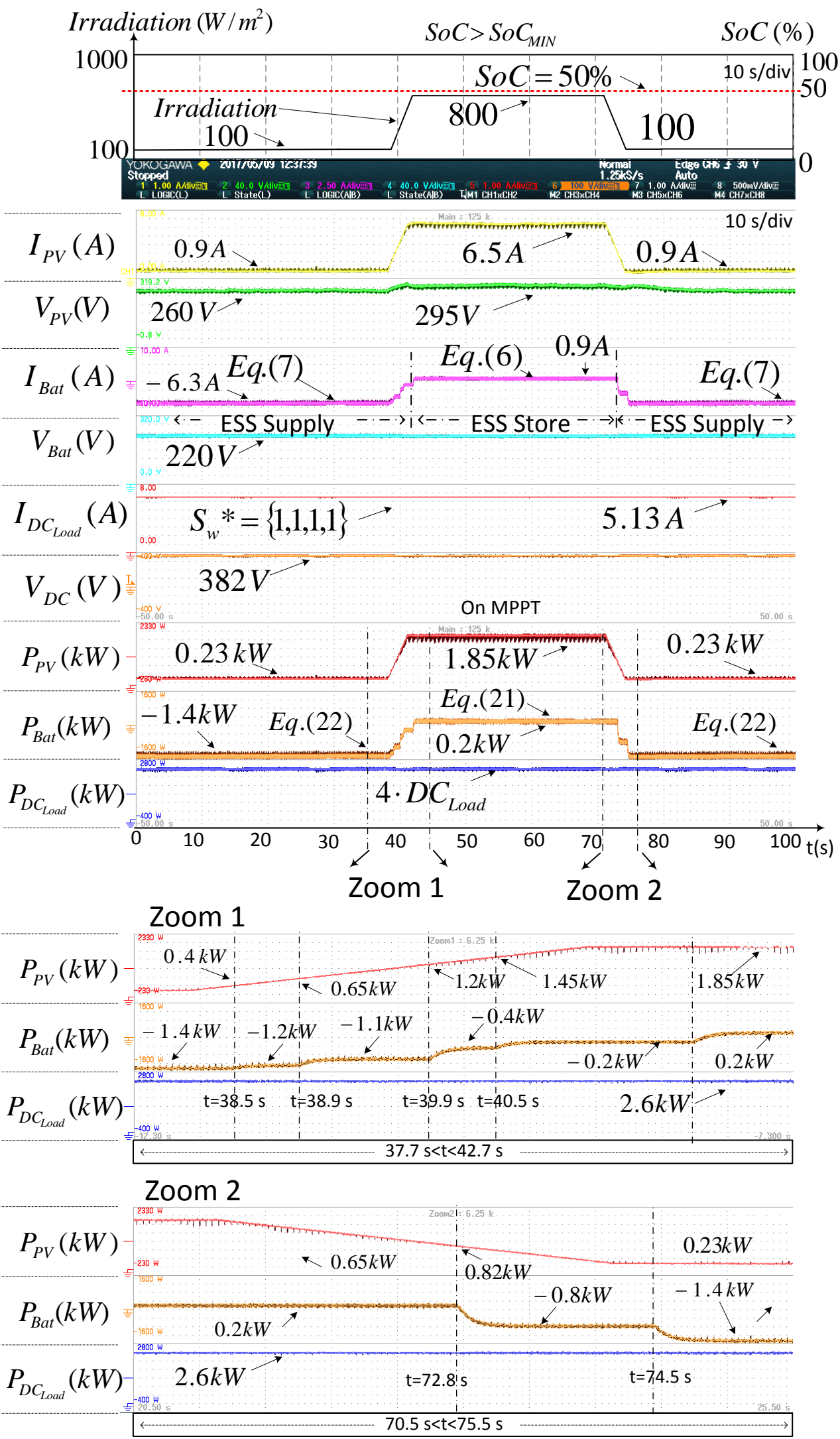

Figure 9. Experiment \#1. Evolution of the currents, the power exchange and voltage in the DC microgrid for changes in the irradiation at a $S o C>S o C_{M I N}$. 


\subsection{Experiment \#2}

The ESS is initially at a SoC $\leq 20 \%$ (discharged). MGCC applies the load shedding functionality; see Figure 10. Two zoom images can be observed in the lower plot from Figure 10. In Zoom 1 it is shown the detection by the MGCC of an increase in PV system generation. In Zoom 2 it is shown the detection of a decrease in PV system generation. The analysis is performed according to the following time intervals:

Interval $2.1(0 \mathrm{~s}<t<28 \mathrm{~s})$ : The irradiation level is $100 \mathrm{~W} / \mathrm{m}^{2}$ and the PV source works at its MPP, providing $P_{P V}=230 \mathrm{~W}$ to the DC bus. That irradiation is not enough to feed all the loads. Considering that the ESS is discharged $(\mathrm{SoC}<20 \%)$, the MGCC transfers the maximum possible power from the grid $\left(P_{I L C} D C=-1 \mathrm{~kW}\right)$ to the DC bus through the ILC, and applies the load shedding functionality. Taking into account that the available power at the DC bus $(1.28 \mathrm{~kW})$ is not enough to feed two loads, the MGCC connects only one DC load $\left(P_{D C_{-} \text {Load }}=0.65 \mathrm{~kW}\right)$, using the rest of this power for charging the batteries at $P_{\text {Bat }}=0.55 \mathrm{~kW}$.

Interval $2.2(28 \mathrm{~s}<t<31 \mathrm{~s})$ : The irradiation increases from $100 \mathrm{~W} / \mathrm{m}^{2}$ to $800 \mathrm{~W} / \mathrm{m}^{2}$ in $3 \mathrm{~s}$, which makes the MGCC to apply the load shedding functionality. See Zoom 1 of Figure 10.

At $\mathrm{t}=29 \mathrm{~s}$ the PV source works at its MPP delivering $P_{P V}=0.95 \mathrm{~kW}$, whereas $P_{I L C} D C=-1 \mathrm{~kW}$. At that instant the MGCC detects that the available power at the DC bus is enough to feed two of the loads $\left(P_{D C \_ \text {Load }}=1.3 \mathrm{~kW}\right)$. The MGCC takes into account the hysteresis level in that connection and changes the setpoint $P_{E S S}{ }^{*}$ from $0.55 \mathrm{~kW}$ to $0.6 \mathrm{~kW}$. Note that at $t=29 \mathrm{~s}$, after the connection of the two loads, only $\left|P_{I L C} D C\right| \leq 1 \mathrm{~kW}$ is taken from the grid. This ensures a minimum level of power available in the DC bus.

At $t=30.2 \mathrm{~s}$, the PV source works at its MPP delivering $P_{P V}=1.6 \mathrm{~kW}$, being $P_{I L C} D C=-1 \mathrm{~kW}$. At that instant the MGCC detects that the available power at the DC bus, taking into account the hysteresis level, is enough to feed three of the loads $\left(P_{D C \_L o a d}=1.95 \mathrm{~kW}\right)$. The MGCC connects three loads and changes the setpoint $P_{E S S}$ * of the ESS from $0.6 \mathrm{~kW}$ to $0.65 \mathrm{~kW}$.

Interval $2.3(55.5 \mathrm{~s}<t<65.5 \mathrm{~s})$ : The irradiation decreases from $800 \mathrm{~W} / \mathrm{m}^{2}$ to $100 \mathrm{~W} / \mathrm{m}^{2}$ in $3 \mathrm{~s}$. The MGCC keeps the load shedding functionality activated. See Zoom 2 of Figure 10.

At $t=64.3 \mathrm{~s}$ the PV source works at its MPP delivering $P_{P V}=0.23 \mathrm{~kW}$, whereas $P_{I L C} \_D C=-1 \mathrm{~kW}$. At that instant the MGCC detects that the available power at the DC bus taking into account the hysteresis level is enough to feed two of the loads $\left(P_{D C_{-} \text {Load }}=1.3 \mathrm{~kW}\right)$. MGCC connects two loads and changes the setpoint $P_{E S S}{ }^{*}$ of the ESS from $0.65 \mathrm{~kW}$ to $0.5 \mathrm{~kW}$. Note that at $t=64.3 \mathrm{~s}$, after the connection of the two loads, only $\left|P_{I L C \_D C}\right| \leq 1 \mathrm{~kW}$ is taken from the grid. This ensures a minimum level of power available in the DC bus. 


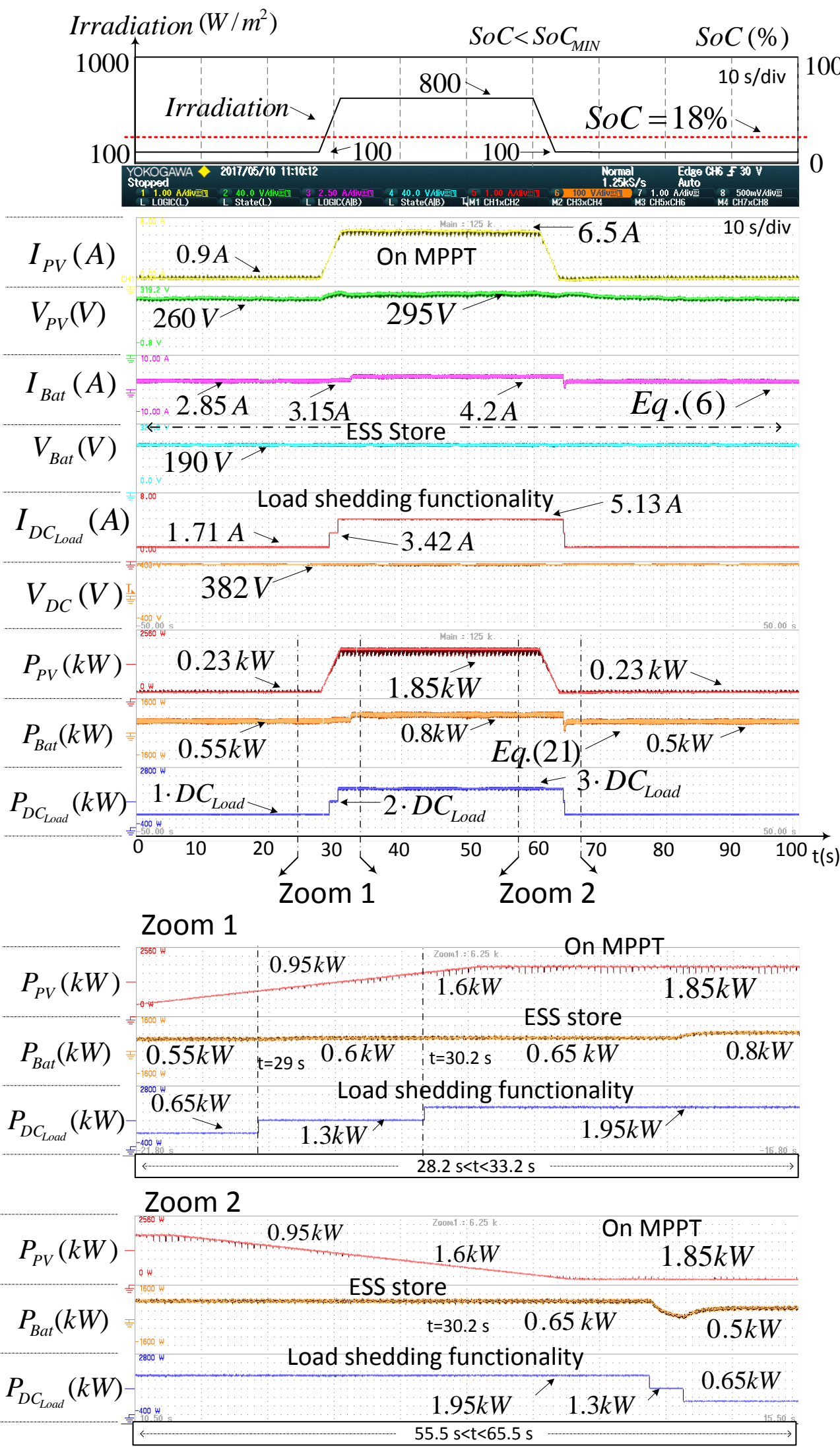

Figure 10. Experiment \#2. Evolution of the currents, the power exchange and voltage in the DC microgrid for changes in the irradiation at a $S o C<S o C_{M I N}$. 


\subsection{Experiment \#3}

The ESS is initially at a $S o C \geq S o C_{M I N}$. At $t=21.2 \mathrm{~s}$ the $S o C$ changes at a $S o C<S o C_{M I N}$, see Figure 11 . Three zoom images can be observed in the lower plot from Figure 11. Zoom 1 shows the details of the power flows in the MG when the MGCC detects that $S o C<S o C_{M I N}$. In Zoom 2 it is shown the detection by the MGCC of an increase in PV generation. In Zoom 3 it is shown the detection of a decrease in PV generation. The analysis is performed according to the following time intervals:

Interval $3.1(0 \mathrm{~s}<t<21.2 \mathrm{~s})$ : The irradiation level is $100 \mathrm{~W} / \mathrm{m}^{2}$ and the PV source works at its MPP, providing $P_{P V}=230 \mathrm{~W}$ to the DC bus. That irradiation is not enough to feed all the loads. Taking into account that the $\mathrm{SoC}>20 \%$, the MGCC transfers the maximum possible power from the grid $\left(P_{I L C} D C=-1 \mathrm{~kW}\right)$ to the DC bus through the ILC. MGCC keeps all the DC loads connected and orders the ESS supplying all the power required by the DC bus, $P_{\text {Bat }}=-1.4 \mathrm{~kW}$.

At $t=21.2 \mathrm{~s}$; the PV source works at its MPP delivering $P_{P V}=230 \mathrm{~W}$. That irradiation is not enough to feed all the loads. Considering that MGCC detects that the ESS is discharged, $S o C<20 \%$. MGCC transfers the maximum possible power from the grid $\left(P_{I L C} D C=-1 \mathrm{~kW}\right)$ to the DC bus through the ILC. MGCC starts a transition from $S w=$ On to $S w=$ Off and applies the load shedding functionality. Taking into account that the available power at the DC bus $(1.23 \mathrm{~kW})$ is not enough to feed two loads, MGCC connects only one DC load $\left(P_{D C \_L o a d}=0.65 \mathrm{~kW}\right)$. The rest of the available power is used for charging the batteries. MGCC changes the setpoint $P_{E S S}{ }^{*}$ of the ESS from $-1.4 \mathrm{~kW}$ to $0.55 \mathrm{~kW}$.

Zoom 1 of Figure 11 depicts $P_{\text {Bat }}$ and its behavior to sudden changes of $P_{E S S}{ }^{*}$ from $1.4 \mathrm{~kW}$ to $0.55 \mathrm{~kW}$. If $P_{E S S}{ }^{*}$ is negative, the ESS is supplying power to the DC bus according to Equation (21), whereas if $P_{E S S}{ }^{*}$ is positive, the batteries are charged according to Equation (20).

Interval $3.2(36.6 \mathrm{~s}<t<41.2 \mathrm{~s})$ : The irradiation increases from $100 \mathrm{~W} / \mathrm{m}^{2}$ to $800 \mathrm{~W} / \mathrm{m}^{2}$ in $3 \mathrm{~s}$. See Zoom 2 of the Figure 11. The MGCC detects an increase in PV generation. The PV source works at its MPP. That irradiation is not enough to feed all the loads. Considering that the ESS is discharged $(\mathrm{SoC}<20 \%)$, the batteries are charged according to Equation (20). MGCC transfers the maximum possible power from the grid $\left(P_{I L C} D C=-1 \mathrm{~kW}\right)$ to the DC bus through the ILC, and applies the load shedding functionality.

Interval $3.3(68 \mathrm{~s}<t<74.5 \mathrm{~s})$ : The irradiation decreases from $800 \mathrm{~W} / \mathrm{m}^{2}$ to $100 \mathrm{~W} / \mathrm{m}^{2}$ in $3 \mathrm{~s}$. See Zoom 3 of Figure 11. The MGCC detects a decrease in PV generation. The PV source works at its MPP. That irradiation is not enough to feed all the loads. The ESS is still discharged $(\mathrm{SoC}<20 \%)$. The MGCC transfers the maximum possible power from the grid $\left(P_{I L C} C_{D C}=-1 \mathrm{~kW}\right)$ to the DC bus through the ILC, and applies the load shedding functionality. 


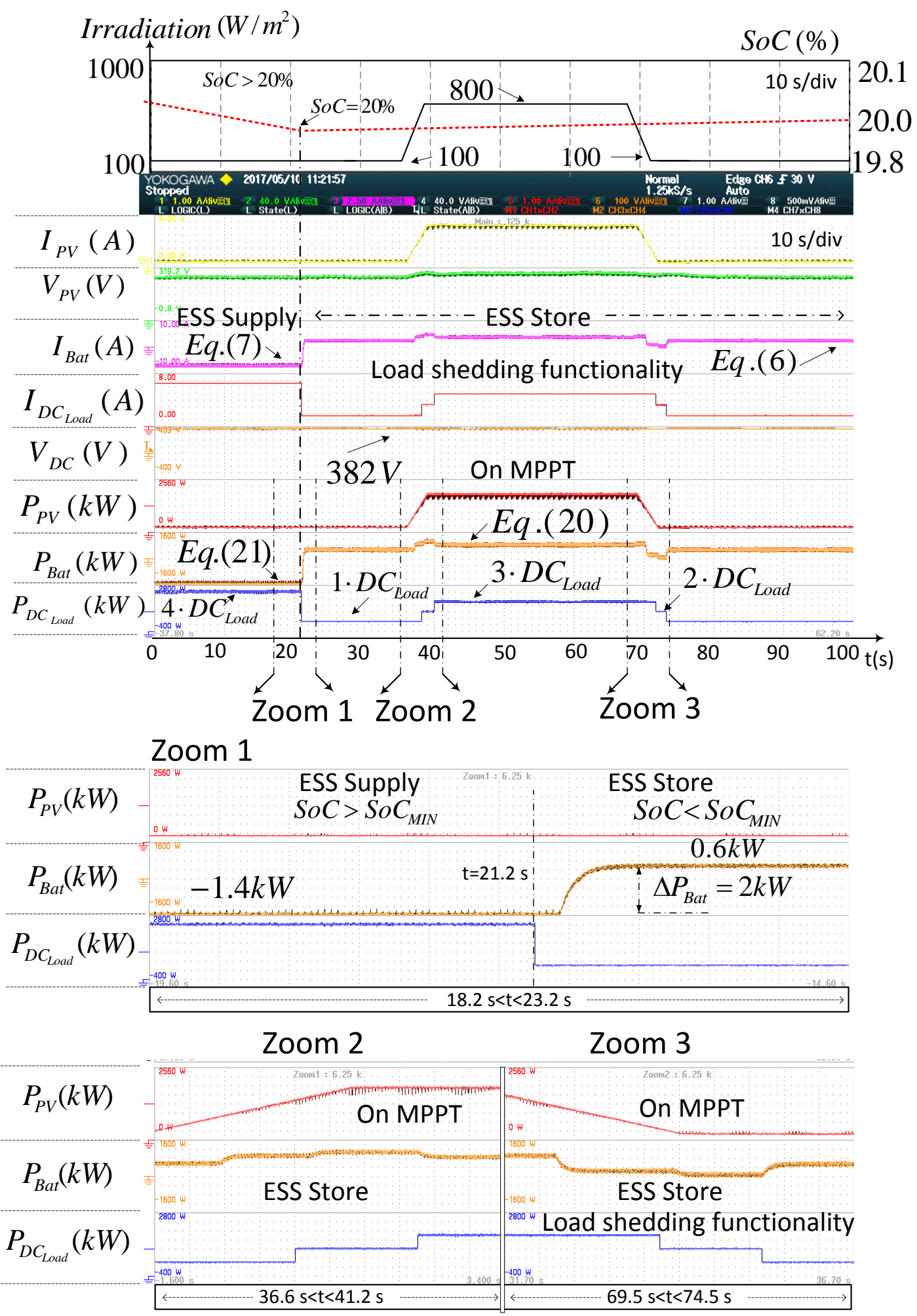

Figure 11. Experiment \#3. Evolution of the currents, the power exchange and voltage in the DC microgrid for changes in the SoC.

\subsection{Experiment \#4}

The communication delays and the running time of the power management algorithm can be observed in Figure 12. The RS485 communication bus baud rate is 9600 bps. In the Figure 12 (full capture) the power management algorithm is executed every $250 \mathrm{~ms}(4 \mathrm{~Hz})$ performing the following 
tasks: request the measurements of voltages and currents to all devices in the microgrid, calculation of instantaneous powers references of the devices and the transmission of the references to the devices. The MGCC processing time of these tasks are shown in Table 4.

Table 4. Processing time used by the algorithms on the MGCC.

\begin{tabular}{cc}
\hline MGCC Algorithm Tasks & Processing Time \\
\hline Measurement and setpoint: & - \\
\hline $\begin{array}{c}\text { Request and receive data } \\
\text { Calculate of references } \\
\text { Send power state refereces }\end{array}$ & $70 \mathrm{~ms}$ \\
\hline Message processing & - \\
\hline $\begin{array}{c}\text { Get command and values } \\
\text { Calculate the references } \\
\text { Build the response message }\end{array}$ & $200 \mu \mathrm{s}$ \\
\hline
\end{tabular}

Three different zoom times about intervals of the RS485 communication of Figure 12 (full capture) are shown.

The Zoom 1 of Figure 12 corresponds to $500 \mathrm{~ms}$, the Zoom 2 of Figure 12 corresponds to $75 \mathrm{~ms}$ and the Zoom 3 of Figure 12 corresponds to $2 \mathrm{~ms}$. In Zoom 1 of the Figure 12 it can be observed that the previously described tasks performed every $250 \mathrm{~ms}$ by the MGCC are completed in $70 \mathrm{~ms}$. In Zoom 2 of the Figure 12 it can be observed the detail of the receiving (RX) and transmitting (TX) signals of every microgrid component on the bus RS485: PV generator, ESS, MGCC. In Zoom 3 of the Figure 12 it is shown the time required for the MGCC from the reception of information of the converters and the compute the reference signals to be sent to each element is $200 \mu \mathrm{s}$. The communication transmission delays of the request, response and send operation commands in the DC microgrid are shown in the Table 5 .

The implemented RS485 communication allows the calculation of the power values at several points of the microgrid in a fast and accurate way (see Figure 12). The power management algorithm is executed every $250 \mathrm{~ms}$ which is time enough to: (i) measure and calculate the generated and demanded powers; (ii) calculate the power references for every converter on stream and (iii) establish the load which can be connected to the DC bus. The most important computation and transmission times have been reported in the Tables 4 and 5 .

Power exchanges among the devices of the MG have been shown in the Figures 9-11. The load shedding functionality is applied when the battery bank is discharged. The batteries can be recharged with the excess available power after load connection/disconnection. The amount of load shedding depends on the available power at the DC bus taking into account a hysteresis level, which improves the reliability of the MG and ensures the safety and stability of the DC bus voltage. The main issue during the data processing is the disconnection/connection of an excessive load during a too long time, which can lead to strong transient disturbances. Therefore, the load demand is measured in real time and sent to the MGCC.

Table 5. Communication delays between the DC/DC power converters and the MGCC.

\begin{tabular}{clcc}
\hline \multirow{2}{*}{ Communication Delays } & \multirow{2}{*}{ MGCC } & \multicolumn{2}{c}{ DC/DC Power Converters } \\
\cline { 3 - 4 } & & ESS & PV \\
\hline Request of the measurement & From MGCC to converter & $3.5 \mathrm{~ms}$ & $3.5 \mathrm{~ms}$ \\
\hline Response of the measurement & From converter to MGCC & $11.5 \mathrm{~ms}$ & $16.8 \mathrm{~ms}$ \\
\hline Send operation command (setpoint) & From MGCC to converter & $15.5 \mathrm{~ms}$ & $4.5 \mathrm{~ms}$ \\
\hline
\end{tabular}


Full capture

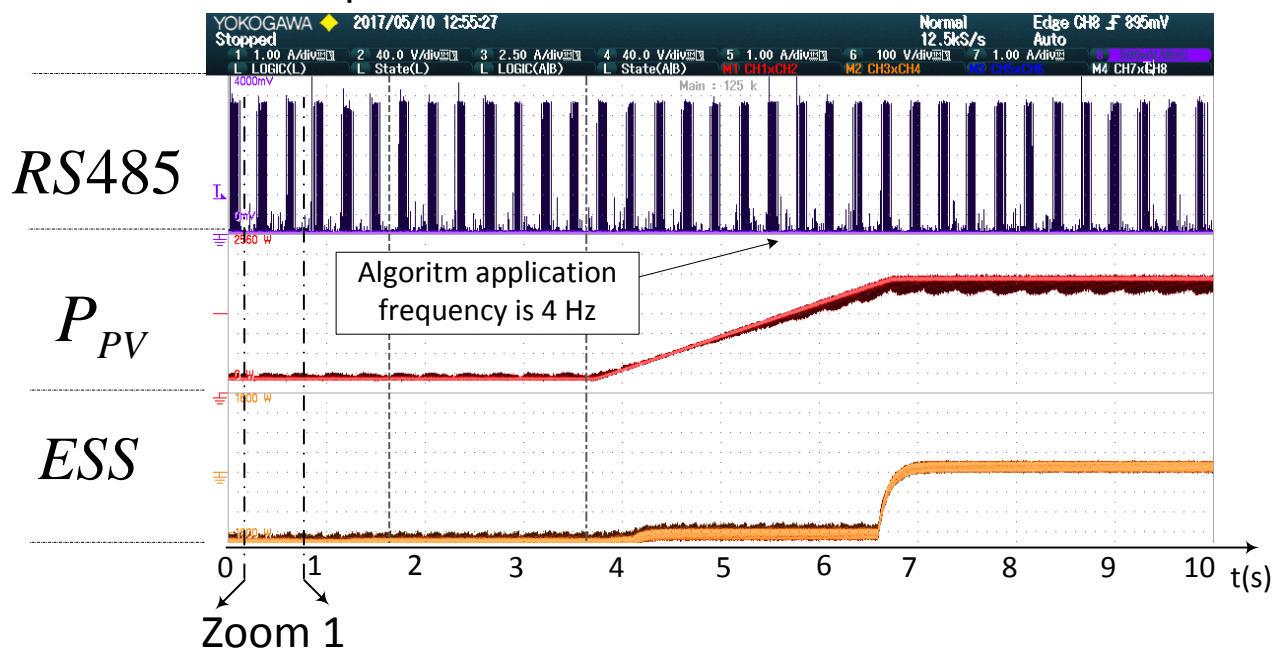

\section{Zoom 1}

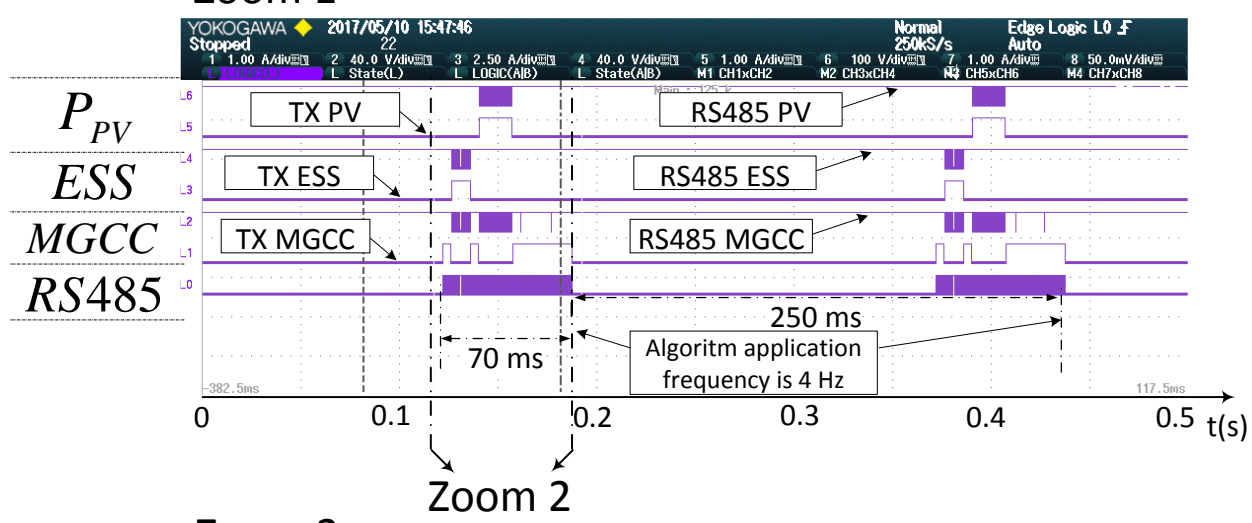

Zoom 2

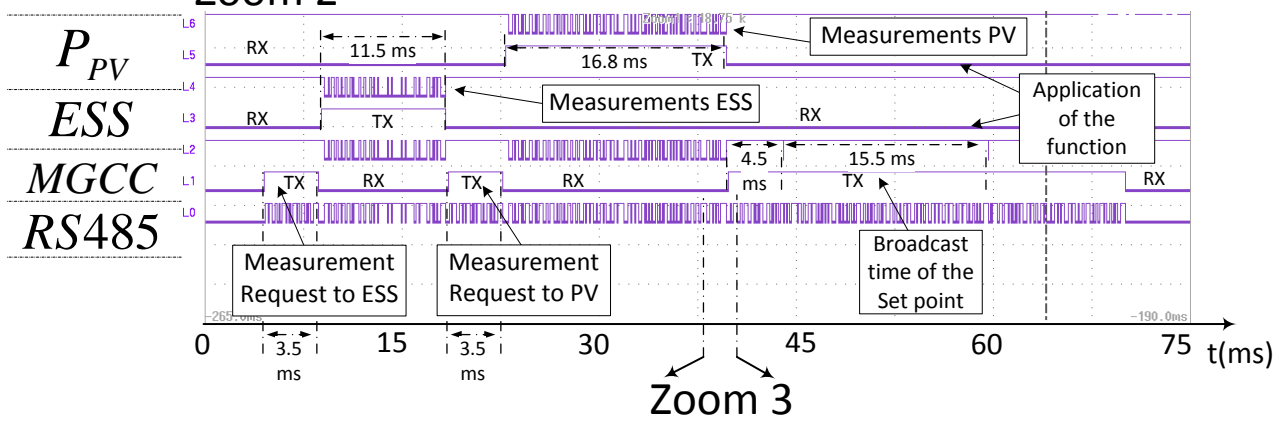

\section{Zoom 3}

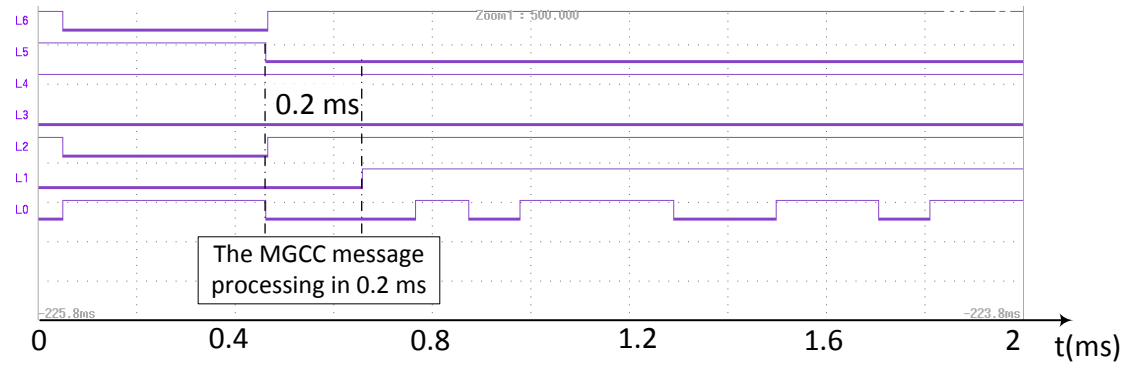

Figure 12. Experiment \#4. Communications delay between the MGCC and two of the microgrid elements. 


\section{Conclusions}

This paper is focused on the centralized control of the power converters connected to a DC microgrid operating in grid-connected mode. The proposed strategy deals with different devices according to their type: generation, storage, interlinking converter and load. A coordinated power flow in the DC microgrid is achieved by means of a low-bandwidth RS485 serial communication system at 9600 bps. This kind of communication is a cost effective solution in MGs.

The secondary control level is performed by means of an MGCC that performs the calculations and communications. The MGCC calculates the suitable power references for every device in real time and broadcasts those values to the MG elements in order to set their status. The power reference of the ESS is determined by considering the additional power needed at the DC bus after having considered the power available at the PV DG and that coming from the ILC.

The power management system of the battery ESS follows the power command defined by the MGCC as a function of the batteries $S o C$ and of the MG status, following the charging procedure to DIN 41773 for VRLA batteries of the ESS. The ESS algorithm operates the batteries at a suitable power level, being compatible with the MG operation mode and the MG available power. The ESS has been chosen to keep the batteries at a relatively high charge level, so that enough energy can be extracted from the batteries when the power demand is higher than the sum of available PV power and maximum grid importable power. This feature allows to temporary feed a power higher than the maximum importable power defined in the electricity contract, thus reducing the electricity bill, which is higher the higher the maximum importable power established by the contract.

The experimental results demonstrate that the power strategies which have been integrated allow the control of the power dispatch inside the DC microgrid properly, respecting the established power limits. It has been demonstrated that smooth transients in the MG are obtained in some common and extreme scenarios, in spite of strong changes in the power flows inside the MG.

Acknowledgments: This work has been cofinanced by the Spanish Ministry of Economy and Competitiveness (MINECO) and by the European Regional Development Fund (ERDF) under Grant ENE2015-64087-C2-2.

Author Contributions: Robert Salas-Puente, Emilio Figueres and Gabriel Garcerá proposed the main idea, conceived and designed the experiments; Robert Salas-Puente and R. González-Medina performed the experiments; Silvia Marzal designed the communication; Silvia Marzal and Raúl González-Medina reviewed the article; Robert Salas-Puente, Emilio Figueres and Gabriel Garcerá wrote this paper.

Conflicts of Interest: The authors declare no conflict of interest.

\section{Abbreviations}

$\begin{array}{ll}P_{P V} & \text { Power supplied by the PV arrays } \\ P_{P V} & \text { Power supplied by the PV arrays seen from the DC bus } \\ P_{D C L o a d} & \text { Overall power consumed by the DC loads } \\ P_{\text {Grid }} & \text { Power injected from the DC microgrid to the grid } \\ P_{I L C} A C & \text { Power injected from the DC bus to the grid by the ILC, measured at the AC side of the ILC } \\ P_{I L C} D C & \text { Power injected from the DC bus to the grid by the ILC, measured at the DC side of the ILC } \\ P_{E S S} & \text { Battery charge power seen from the DC bus } \\ P_{B a t} & \text { Battery charge power } \\ \eta_{E E S} & \text { Efficiency of the ESS } \\ \eta_{P V} & \text { Efficiency of the PV DC/DC converter } \\ \eta_{I L C} & \text { Efficiency of the ILC } \\ I_{G \text { Grid }} & \text { RMS Current injected from the DC microgrid to the grid } \\ V_{G r i d} & \text { RMS value of the grid voltage } \\ \omega & \text { Grid angular frequency } \\ \varphi & \text { Grid phase } \\ I_{D C L o a d} & \text { Overall current consumed by the DC loads } \\ V_{D C} & \text { DC bus voltage }\end{array}$




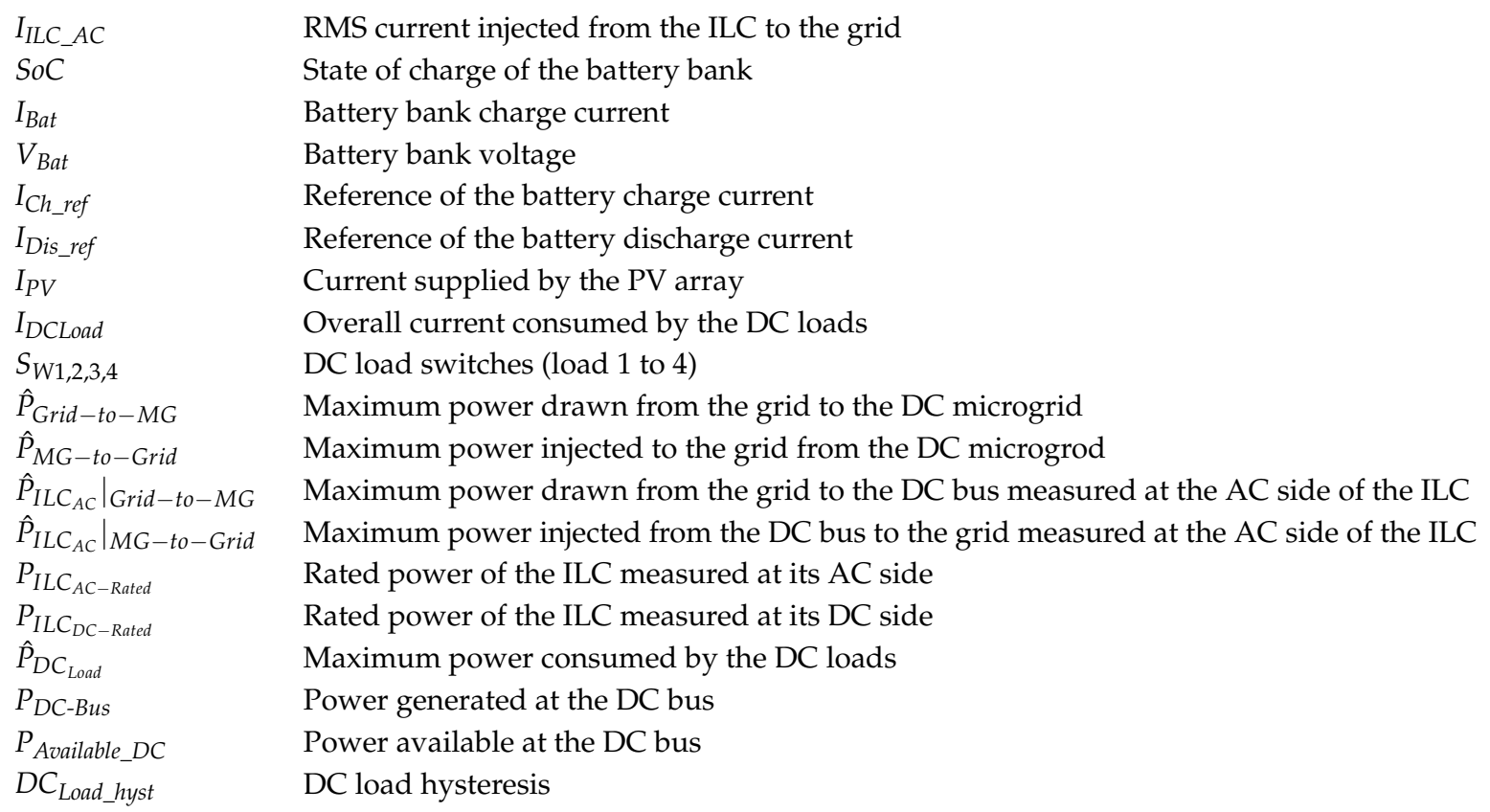

\section{References}

1. Dragičević, T.; Lu, X.; Vasquez, J.C.; Guerrero, J.M. DC Microgrids-Part I: A Review of Control Strategies and Stabilization Techniques. IEEE Trans. Power Electron. 2016, 31, 4876-4891.

2. Baek, J.; Choi, W.; Chae, S. Distributed Control Strategy for Autonomous Operation of Hybrid AC/DC Microgrid. Energies 2017, 10, 373. [CrossRef]

3. Patrao, I.; Figueres, E.; Garcerá, G. González-Medina, Microgrid architectures for low voltage distributed generation. Renew. Sustain. Energy Rev. 2015, 43, 415-424. [CrossRef]

4. Ma, T.T.H.; Yahoui, H.; Vu, H.G.; Siauve, N.; Morel, H. A Control Strategy of DC Building Microgrid Connected to the Neighborhood and AC Power Network. Buildings 2017, 7, 42. [CrossRef]

5. Lin, P.; Wang, P.; Xiao, J.; Wang, J.; Jin, C.; Tang, Y. An Integral Droop for Transient Power Allocation and Output Impedance Shaping of Hybrid Energy Storage System in DC Microgrid. IEEE Trans. Power Electron. 2017. [CrossRef]

6. Liu, X.; Wang, P.; Loh, P.C. A hybrid AC/DC micro-grid. In Proceedings of the 2010 Conference IPEC, Singapore, 27-29 October 2010; pp. 746-751.

7. Wang, P.; Liu, X.; Jin, C.; Loh, P.; Choo, F. A hybrid AC/DC micro-grid architecture, operation and control. In Proceedings of the 2011 IEEE Power and Energy Society General Meeting, Detroit, MI, USA, 24-29 July 2011; pp. 1-8.

8. Kakigano, H.; Miura, Y.; Ise, T. Low-Voltage Bipolar-Type DC Microgrid for Super High Quality Distribution. IEEE Trans. Power Electron. 2010, 25, 3066-3075. [CrossRef]

9. Zhang, L.; Wu, T.; Xing, Y.; Sun, K.; Gurrero, J.M. Power control of DC microgrid using DC bus signaling. In Proceedings of the 2011 Twenty-Sixth Annual IEEE Applied Power Electronics Conference and Exposition (APEC), Fort Worth, TX, USA, 6-11 March 2011; pp. 1926-1932.

10. Salomonsson, D.; Soder, L.; Sannino, A. An Adaptive Control System for a DC Microgrid for Data Centers. IEEE Trans. Ind. Appl. 2008, 44, 1910-1917. [CrossRef]

11. Lie, X.; Dong, C. Control and Operation of a DC Microgrid with Variable Generation and Energy Storage. IEEE Trans. Power Deliv. 2011, 26, 2513-2522.

12. Liu, X.; Wang, P.; Loh, P.C. A Hybrid AC/DC Microgrid and Coordination Control. IEEE Trans. Smart Grid 2013, 2, 278-286.

13. Nejabatkhah, F.; Li, Y.W. Overview of Power Management Strategies of Hybrid AC/DC Microgrid. IEEE Trans. Power Electron. 2015, 30, 7072-7089. [CrossRef] 
14. Lu, X.; Guerrero, J.M.; Sun, K.; Vasquez, J.C. An improved droop control method for DC microgrids based on low bandwidth communication with DC bus voltage restoration and enhanced current sharing accuracy. IEEE Trans. Power Electron. 2014, 29, 1800-1812. [CrossRef]

15. Chen, D.; Xu, L. Autonomous DC voltage control of a DC microgrid with multiple slack terminals. IEEE Trans. Power Syst. 2012, 27, 1897-1905. [CrossRef]

16. Varghese, A.; Chandran, L.R.; Rajendran, A. Power flow control of solar PV based islanded low voltage DC microgrid with battery management system. In Proceedings of the 2016 IEEE 1st International Conference on Power Electronics, Intelligent Control and Energy Systems (ICPEICES), Delhi, India, 4-6 July 2016; pp. 1-6.

17. Josep Guerrero, J.V. Hierarchical Control of Droop-Controlled AC and DC Microgrids-A General Approach toward Standardization. IEEE Trans. Ind. Electron. 2011, 58, 158-172. [CrossRef]

18. Vasquez, J.C.; Guerrero, J.M.; Miret, J.; Castilla, M.; de Vicuna, L.G. Hierarchical Control of Intelligent Microgrids. IEEE Ind. Electron. Mag. 2010, 4, 23-29. [CrossRef]

19. Meng, L.; Savaghebi, M.; Andrade, F.; Vasquez, J.C.; Guerrero, J.M.; Graells, M. Microgrid central controller development and hierarchical control implementation in the intelligent microgrid lab of Aalborg University. In Proceedings of the Applied Power Electronics Conference and Exposition (APEC), Charlotte, NC, USA, 15-19 March 2015; pp. 2585-2592.

20. Unamuno, E.; Barrena, J.A. Hybrid AC/DC microgrids-Part II: Review and classification of control strategies. Renew. Sustain. Energy Rev. 2015, 52, 1123-1134. [CrossRef]

21. Feng, X.; Shekhar, A.; Yang, F.E.; Hebner, R.; Bauer, P. Comparison of Hierarchical Control and Distributed Control for Microgrid. Electr. Power Compon. Syst. 2017, 45, 1043-1056. [CrossRef]

22. Marzal, S.; González-Medina, R.; Salas-Puente, R.; Figueres, E.; Garcerá, G. A Novel Locality Algorithm and Peer-to-Peer Communication Infrastructure for Optimizing Network Performance in Smart Microgrids. Energies 2017, 10, 1275. [CrossRef]

23. Kaur, A.; Kaushal, J.; Basak, P. A review on microgrid central controller. Renew. Sustain. Energy Rev. 2016, 55, 338-345. [CrossRef]

24. Begum, M.; Abuhilaleh, M.; Li, L.; Zhu, J. Distributed secondary voltage regulation for autonomous microgrid. In Proceedings of the 20th International Conference on Electrical Machines and Systems (ICEMS), Sydney, Australia, 11-14 August 2017; pp. 1-6.

25. Wu, D.; Tang, F.; Dragicevic, T.; Guerrero, J.M.; Vasquez, J.C. Coordinated Control Based on Bus-Signaling and Virtual Inertia for Islanded DC Microgrids. IEEE Trans. Smart Grid 2015, 6, 2627-2638. [CrossRef]

26. Shi, D.; Chen, X.; Wang, Z.; Zhang, X.; Yu, Z.; Wang, X.; Bian, D. A Distributed Cooperative Control Framework for Synchronized Reconnection of a Multi-Bus Microgrid. IEEE Trans. Smart Grid 2017, PP, 1. [CrossRef]

27. Dou, C.; Zhang, Z.; Yue, D.; Zheng, Y. MAS-Based Hierarchical Distributed Coordinate Control Strategy of Virtual Power Source Voltage in Low-Voltage Microgrid. IEEE Access 2017, 5, 11381-11390. [CrossRef]

28. Bracale, A.; Caramia, P.; Carpinelli, G.; Mancini, E.; Mottola, F. Optimal control strategy of a DC micro grid. Int. J. Electr. Power Energy Syst. 2015, 67, 25-38. [CrossRef]

29. Hajar, K.; Hably, A.; Bacha, S.; Elrafhi, A.; Obeid, Z. Optimal centralized control application on microgrids. In Proceedings of the 2016 3rd International Conference on Renewable Energies for Developing Countries (REDEC), Zouk Mosbeh, Lebanon, 13-15 July 2016; pp. 1-6.

30. Yue, J.; Hu, Z.; Li, C.; Vasquez, J.C.; Guerrero, J.M. Economic Power Schedule and Transactive Energy through an Intelligent Centralized Energy Management System for a DC Residential Distribution System. Energies 2017, 10, 916. [CrossRef]

31. Gao, L.; Liu, Y.; Ren, H.; Guerrero, J.M. A DC Microgrid Coordinated Control Strategy Based on Integrator Current-Sharing. Energies 2017, 10, 1116. [CrossRef]

32. Hooppecke. Operating Instructions Valve Regulated Stationary Lead-Acid Batteries. Available online: http:/ / www.hoppecke-us.com/tl_files/hoppecke/Documents/HO-US/Operating_Instructions_sealed_ stationary_lead_acid_batteries_en1111.pdf (accessed on 13 October 2017).

33. TAB Batteries. Available online: http://www.tabspain.com/wp-content/uploads/informacion-tecnica/ renovables / curvas-y-tablas / din-41773-y-din-41774-para-baterias-pzs.pdf (accessed on 13 October 2017).

34. Zhao, J.; Dörfler, F. Distributed control and optimization in DC microgrids. Automatica 2015, 61, 18-26. [CrossRef] 
35. Eghtedarpour, N.; Farjah, E. Power Control and Management in a Hybrid AC/DC Microgrid. IEEE Trans. Smart Grid 2014, 5, 1494-1505. [CrossRef]

36. Support, T. Installation, Commissioning and Operation Handbook for Gel-Vrla-Batteries. 2003. Available online: http://www.sonnenschein.org/PDF\%20files/GelHandbookPart2.pdf (accessed on 13 October 2017).

37. AlLee, G.; Tschudi, W. Edison Redux: 380 Vdc Brings Reliability and Efficiency to Sustainable Data Centers. IEEE Power Energy Mag. 2012, 10, 50-59. [CrossRef]

38. Joseph, A.; Shahidehpour, M. Battery storage systems in electric power systems. In Proceedings of the 2006 IEEE Power Engineering Society General Meeting, Montreal, QC, Canada 18-22 June 2006; p. 8.

39. Aryani, D.R.; Song, H. Coordination Control Strategy for AC/DC Hybrid Microgrids in Stand-Alone Mode. Energies 2016, 9, 469. [CrossRef]

40. Dragičević, T.; Guerrero, J.M.; Vasquez, J.C.; Škrlec, D. Supervisory Control of an Adaptive-Droop Regulated DC Microgrid with Battery Management Capability. IEEE Trans. Power Electron. 2014, 29, 695-706. [CrossRef]

41. Tian, Y.; Li, D.; Tian, J.; Xia, B. State of charge estimation of lithium-ion batteries using an optimal adaptive gain nonlinear observer. Electrochim. Acta 2017, 225, 225-234. [CrossRef]

42. Golestan, S.; Monfared, M.; Guerrero, J. Second order generalized integrator based reference current generation method for single-phase shunt active power filters under adverse grid conditions. In Proceedings of the Power Electronics, Drive Systems and Technologies Conference (PEDSTC), Tehran, Iran, 13-14 February 2013; pp. 510-517.

43. Jianfang, X.; Peng, W. Multiple modes control of household DC microgrid with integration of various renewable energy sources. In Proceedings of the IECON 2013-39th Annual Conference of the IEEE Industrial Electronics Society, Vienna, Austria, 10-13 November 2013; pp. 1773-1778.

44. Ciobotaru, M.; Teodorescu, R.; Blaabjerg, F. A new single-phase PLL structure based on second order generalized integrator. In Proceedings of the 2006 37th IEEE Power Electronics Specialists Conference, Jeju, Korea, 18-22 June 2006; pp. 1-6.

45. Standard for Interconnecting Distributed Resources with Electric Power Systems. Available online: http: / / fglongatt.org/OLD/Archivos / Archivos/SistGD/IEEE1547.pdf (accessed on 13 October 2017).

(C) 2017 by the authors. Licensee MDPI, Basel, Switzerland. This article is an open access article distributed under the terms and conditions of the Creative Commons Attribution (CC BY) license (http://creativecommons.org/licenses/by/4.0/). 